\title{
The effect of matrix on Highly tunable shape properties of aromatic disulfide based epoxy vitrimers
}

Itxaso Azcune, ${ }^{* a}$ Arrate Huegun, ${ }^{a}$ Alaitz Ruiz de Luzuriaga, ${ }^{a}$ Eduardo Saiz ${ }^{b}$ and Alaitz Rekondo ${ }^{a}$

${ }^{a}$ CIDETEC, Basque Research and Technology Alliance (BRTA), Paseo Miramón, 196, 20014 Donostia-San

Sebastián, Spain.*Corresponding author:iazcune@cidetec.es

${ }^{b}$ Department of Materials, Centre for Advanced Structural Ceramics, Imperial College London, London $S W 72 A Z, U K$.

$\dagger$ Electronic Supplementary Information (ESI) available.

\section{Key words}

Vitrimer, aromatic disulfide, epoxy network, shape memory, reprocessability

\begin{abstract}
Aromatic disulfide based vitrimers show elasticity driven shape-memory and plastic reprocessability via associative rearrangement of dynamic covalent crosslinks. Those processess represent the two sides of a coin: the storage and relaxation of the strain energy caused by a deformation load. The key temperatures that trigger the underlying mechanisms, i.e. phase transition and disulfide exchange reaction, are extremely sensitive to the molecular structure of the polymer and under certain condition overlap. To gain insight on the relationship between the structure, dynamic and shape-changing properties, five aromatic disulfide-based epoxy networks with a range of $\mathrm{T}_{\mathrm{g}}$ values $\left(32-142{ }^{\circ} \mathrm{C}\right)$, molecular structure and crosslink densities (2252-462 mol $\mathrm{m}^{-3}$ ) were synthesized. The epoxy matrices were formulated combining different ratios of rigid bisphenol A diglycidyl ether (DGEBA) and flexible poly(propylene glycol) diglycidic ether (DGEPPG) epoxy monomers crosslinked by 4-aminophenyldisulfide hardener.
\end{abstract}

\section{Introduction}

The combination of elasticity driven shape-memory and plastic reprocessability via associative rearrangement of dynamic covalent crosslinks has derived into fascinating shape-changing materials [1].

Shape memory polymers (SMPs) are known since the 1950s and they have been applied in a variety of areas, from self-deployable aerospace structures to biomedical applications [2,3]. From the structural perspective, SMPs are chemically or physically crosslinked materials that present a thermal transition $\left(T_{\text {trans }}\right)$ that plays as a switch between the different shapes, i.e. the permanent and temporary shapes. In case of amorphous polymers this occurs at glass transition temperature $\left(\mathrm{T}_{\mathrm{g}}\right)$ when the material becomes soft upon heating and brittle upon cooling. The programming starts by heating and applying a deformation on the permanent shape, followed by a rapid cooling to lock the new temporary shape. The deformation energy is stored in the new strained chain conformation until the increase of temperature permits molecular mobility and triggers the recovery of the permanent shape. The spontaneous shape recovery is attributed to the tendency of the network to increase its entropy until the crosslinking sites return to their original spatial positions, and it is driven and limited by the elastic properties of the material. 
One feature of traditional crosslinked polymers or thermosets is that once the polymerization reaction takes place, the material cannot be reshaped or reprocessed above the elastic limits without irreversible structural damage. However, the incorporation of dynamic chemistry in polymer networks opened new possibilities [47]. There are materials, known as vitrimers, crosslinked with exchangeable bonds that can rearrange thermally (or under another stimulus) via a associative-mechanism and maintain network integrity [8-10]. This malleability of the network provides the crosslinked material with new functionalities such as, reprocessing, repairing and recycling, and allows setting new relaxed permanent shapes. There a two transition temperatures that drastically affect the viscoelastic properties of vitrimers: the freezing topology temperature $\left(\mathrm{T}_{\mathrm{v}}\right)$ and the glass transition temperature $\left(\mathrm{T}_{\mathrm{g}}\right) . \mathrm{T}_{\mathrm{v}}$ represents the temperature below which the chemical exchange is expected to be negligible within the network. It is theoretically defined as the temperature at which the viscosity is $10^{12} \mathrm{~Pa} \mathrm{~s}$ [11-14]. Tg is the temperature at which the materials turns from a glassy to a rubbery state. Only when those two temperatures are exceeded, time-dependent relaxation yields a new relaxed shape.

SM vitrimers represent a paradigm of smart and modulable shape-changing materials. Those materials can be programmed to change temporary shapes under external stimuli and be recycled into new relaxed shapes albeit their crosslinked molecular structure.The majority of reported SM epoxy vitrimers present $\mathrm{T}_{\mathrm{g}} \mathrm{s}$, in the range of $70-100{ }^{\circ} \mathrm{C}$ and rely on catalyzed transesterification for their plasticity which requires high temperatures (in the range of $160-200{ }^{\circ} \mathrm{C}$ ) to be efficiently reprocessed [1, 15-19]. Those SM epoxy vitrimers present a remarkable thermal gap between the shape-memory programming temperature and network rearrangement temperature $\left(\mathrm{T}_{\mathrm{v}}>>\mathrm{T}_{\mathrm{g}}\right)$, and thus, $\mathrm{SM}$ can be programed without endangering the storage of the strain energy in the temporary shape by the stress relaxation via crosslink exchange. Interestingly, SM vitrimers provide the opportunity to modulate the extent of shape recoveries by selecting the appropriate conditions to induce stress relaxation when setting the temporary shape. That was first shown in strain recovery tests carried out under irradiation using networks with photoinduced plasticity [20]. This is especially critical for $S M$ vitrimers whose $T_{v}$ is lower than $T_{g}$ values. In those cases, the crosslink exchange is only hindered by insufficient molecular mobility (high viscosity), and the time and temperature dependent relaxation begin as soon as the system reaches $\mathrm{T}_{\mathrm{g}}$. Aroamtic disulfide-based vitrimers fall in that category. Aromatic disulfide exchange can take place even at ambient temperature without a need of a catalyst as shown by autonomous room temperature self-healing of aromatic disulfide based poly(urea-urethane) elastomers [21]. The pioneering work carried out on the reprocessing of aromatic disulfide based epoxy vitrimer $\left(\mathrm{T}_{\mathrm{g}} 130{ }^{\circ} \mathrm{C}\right.$ and $\left.\mathrm{T}_{\mathrm{v}} 75^{\circ} \mathrm{C}\right)$, showed that stress relaxation occurred close to $\mathrm{Tg}\left(130{ }^{\circ} \mathrm{C}, 3 \mathrm{~h}\right)$, although higher temperatures $\left(200{ }^{\circ} \mathrm{C}, 20 \mathrm{~s}\right)$ were required for rapid reprocessing [22]. Later, the concept of tunable shape recovery in disulfide base vitrimers was qualitatively demostrated in various shape memory tests by comparing two analogue isosorbide-based epoxies. [23]. Recently, Yang et al. took advantage of the shapechanging properties of aromatic disulfide based network to prepare composites with multi-shape memory by chemically welding materials with different switching temperatures [24]. Research on aromatic disulfide vitrimers is active, and a variety of papers dealing with different aspects, such as the synthesis of vitrimers 
from new epoxy monomers and hardeners [25-27] or the effect of the concentration of exchangeable group concentration on dynamic properties [28], have been reported recently.

Importantly, it has been claimed that the reactivity and the dynamic properties of vitrimers is likely to be influenced by the composition and molecular structure of the polymer matrix [14,29]. Here, we present a systematic characterization of aromatic disulfide-based epoxy vitrimers in order to correlate their viscoelastic, thermo-mechanical and dynamic properties, with the crosslinking density and polarity of the matrix (Figure 1). With that objective in mind, a set of 5 aromatic disulfide-based epoxy vitrimers with a range of $\mathrm{T}_{\mathrm{g}}$ values $\left(142{ }^{\circ} \mathrm{C}-32{ }^{\circ} \mathrm{C}\right)$, molecular structure and crosslink densities (2252-462 mol m $\mathrm{m}^{-3}$ ) were synthesized. Those epoxy matrices were formulated combining different ratios of rigid bisphenol A diglycidyl ether (DGEBA) and flexible poly(propylene glycol) diglycidic ether (DGEPPG) epoxy monomers crosslinked by 4-aminophenyldisulfide (AFD). The structure-property relationship of the material was assessed by TGA, DSC, DMA and swelling tests. Additionally, the tunability of shape memory properties where investigated by visual and quantitative thermomechanical tests. To that end, stress-relaxation has been investigated in order to quantify the dissipation of the strain-energy at relevant temperatures, and the impact of time and temperature on the shape memory properties, i.e. fixity rate $\left(R_{f}\right)$ and recovery rate $\left(R_{r}\right)$, were measured by thermomechanical cycles. Besides, disulfide-free but structurally analogue epoxy thermoset was synthesized starting from DGEBA and poly(propylene glycol) bis(2-aminopropyl ether) (D-230) for comparison purposes.
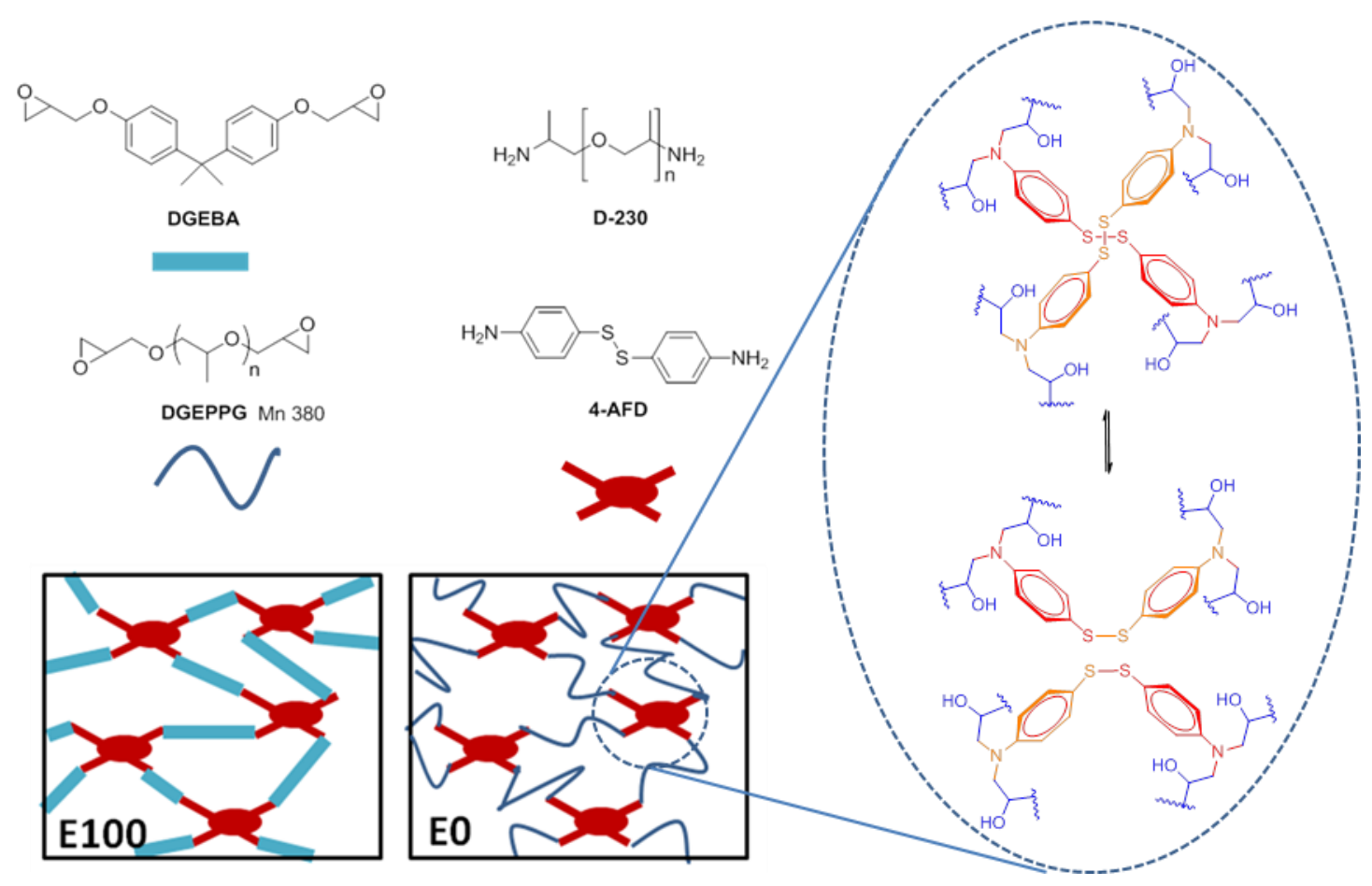

Figure 1: Chemical structure of diepoxy and diamine network components and schematic representation of E100 and E0 networks with exchangeable aromatic disulfide crosslinks.

\section{Experimental}

\section{Materials}


DGEBA-based epoxy resin (Araldite LY1564, epoxide equivalent weight 161-173 $\mathrm{g} \mathrm{eq}^{-1}$ ) was purchased from Huntsman Advanced Materials. Poly(propylene glycol) diglycidyl ether (DGEPPG, Mn=380, epoxide equivalent weight $190 \mathrm{~g} \mathrm{eq}^{-1}$ ) was purchased from Sigma Aldrich. 4-Aminophenyldisulfide (AFD) was purchased from Molekula. Poly(propylene glycol) bis(2-aminopropyl ether) (D-230) was purchased from Sigma Aldrich. All chemicals were used as received.

\section{Synthetic procedures}

Corresponding amounts of DGEBA, DGEPPG and AFD were mixed at $80{ }^{\circ} \mathrm{C}$ and degassed under vacuum (Table 1). The resulting viscous liquid was poured into the interlayer space $(2 \mathrm{~mm})$ between teflon-coated two glass sheets and cured at $120{ }^{\circ} \mathrm{C}$ for $2.5 \mathrm{~h}$ and post-cured at $150{ }^{\circ} \mathrm{C}$ for $2 \mathrm{~h}$. The reference R100 was synthesized starting from DGEBA and D-230 and cured at $100{ }^{\circ} \mathrm{C}$ for $1.5 \mathrm{~h}$ and post-cured at $130{ }^{\circ} \mathrm{C}$ for $1 \mathrm{~h}$. The specimens were cut to the dimensions required for the characterization tests using a knife or a milling machine.

Table 1: Formulation of epoxy networks.

\begin{tabular}{l|l|cccc}
\hline Ref. & DGEBA/DGEPPG/AFD (mol ratio) & DGEBA & DGEPPG & AFD & D-230 \\
\hline R100 & - & $10.00 \mathrm{~g}$ & - & - & $3.72 \mathrm{~g}$ \\
\hline E100 & $1.0 / 0 / 0.55$ & $10.00 \mathrm{~g}$ & - & $4.00 \mathrm{~g}$ & \\
E75 & $0.75 / 0.25 / 0.55$ & $7.29 \mathrm{~g}$ & $2.71 \mathrm{~g}$ & $3.90 \mathrm{~g}$ & - \\
E50 & $0.50 / 0.50 / 0.55$ & $4.72 \mathrm{~g}$ & $5.28 \mathrm{~g}$ & $3.79 \mathrm{~g}$ & - \\
E25 & $0.25 / 0.75 / 0.55$ & $2.30 \mathrm{~g}$ & $7.70 \mathrm{~g}$ & $3.69 \mathrm{~g}$ & - \\
E0 & $0 / 1.0 / 0.55$ & - & $10.00 \mathrm{~g}$ & $3.60 \mathrm{~g}$ & - \\
\hline
\end{tabular}

\section{Characterization techniques}

Fourier transformed infrared (FTIR) spectra were recorded on a JASCO-4100 spectrometer with a diamond ATR probe.

The thermogravimetric analysis (TGA) was performed on a TA Instruments Q500 equipment under air atmosphere at a heating rate of $10{ }^{\circ} \mathrm{C} \min ^{-1}$ from $25{ }^{\circ} \mathrm{C}$ to $800{ }^{\circ} \mathrm{C}$. Isothermal tests were carried out at $200{ }^{\circ} \mathrm{C}$ under air atmosphere.

Differential Scanning Calorimetry (DSC) measurements were performed using a TA Instruments Discovery DSC 25 Auto over a temperature range from $25{ }^{\circ} \mathrm{C}$ to $220{ }^{\circ} \mathrm{C}$ under nitrogen atmosphere. Glass transition temperatures $\left(\mathrm{T}_{\mathrm{g}}\right)$ were obtained as the inflection point of the second heat flow step recorded at a scan rate of $20{ }^{\circ} \mathrm{C} \min ^{-1}$.

Macroscopic scale reprocessing experiments were carried out using a VOGT hot press LaboPress 200T. Small sample pieces were compressed into thin sheets at selected temperature $\left(140{ }^{\circ} \mathrm{C}-190{ }^{\circ} \mathrm{C}\right)$ under 100 bar for 10 minutes. The materials were allowed to reach room temperature in open mold.

Stress-relaxation experiments were carried out in a TA instrument AR2000ex rheometer. Circular samples of $8 \mathrm{~mm}$ diameter were used for the experiments. Samples were allowed one minute to reach the thermal equilibrium at testing temperature. The specimens were stretched by $1 \%$ and the deformation was maintained 
during the test. The decrease of stress over time was recorded and the stress relaxation modulus was calculated.

Thermo mechanical and quantitative shape memory experiments were performed using TA Instruments DMA Q800 equipment equipped with a gas cooling accessory (GCA). For the thermo mechanical experiments the mode of deformation applied was the single cantilever beam, and the dimensions of samples were $12.5 \times 2 \times 17.5 \mathrm{~mm}^{3}$. The temperature range varied from $-40{ }^{\circ} \mathrm{C}$ to $80{ }^{\circ} \mathrm{C}$ for sample $\mathrm{E} 0$; from $25^{\circ} \mathrm{C}$ to $150{ }^{\circ} \mathrm{C}$ for samples E50 and E25; and from $25^{\circ} \mathrm{C}$ to $180{ }^{\circ} \mathrm{C}$ for samples E75 and E100. The temperature dependent behavior was studied by monitoring changes in force and phase angle, keeping the strain amplitude at $0.01 \%$ (within linear viscoelastic region, ESI Figure 6) and frecuency $(1 \mathrm{~Hz})$ constant at a $2{ }^{\circ} \mathrm{C}$ $\mathrm{min}^{-1}$ heating rate. The quantitative shape memory behavior of the materials was evaluated using a tensile film fixture and the controlled force mode. The sample was first heated to $\mathrm{T}_{\text {trans }}$ at $10{ }^{\circ} \mathrm{C} \mathrm{min}^{-1}$ heating rate; then the sample was stretched $1.5 \mathrm{~N} \mathrm{~min}^{-1}$ to $1.5 \mathrm{~N}$. The sample was hold for a controlled exposure time and cooled to $25{ }^{\circ} \mathrm{C}$ at $15{ }^{\circ} \mathrm{C} \mathrm{min}{ }^{-1}$ heating rate maintaining the load (registered strain defined as $\varepsilon_{\text {load }}$ ). After 10 minutes, the sample was unloaded $1.5 \mathrm{~N} \mathrm{~min}^{-1}$ to $0.001 \mathrm{~N}$, the length of the sample in the temporary shape was obtained (registered strain defined as $\varepsilon_{\text {unload }}$ ). The recovery process was then triggered by heating the sample back to $\mathrm{T}_{\text {trans }}$ with a heating rate of $10{ }^{\circ} \mathrm{C} \min ^{-1}$ (registered strain defined as $\varepsilon_{\text {rec}}$ ). Each experiment was repeated twice where 2 and 3 cycles were recorded. The shape fixity ratio $\left(\mathrm{R}_{\mathrm{f}}\right)$ and shape recovery ratio $\left(\mathrm{R}_{\mathrm{r}}\right)$ were determined using the equations 1 and 2 :

$$
\begin{aligned}
& \mathrm{R}_{\mathrm{f}}=\varepsilon_{\text {unload }} / \varepsilon_{\text {load }} \times 100 \% \\
& \mathrm{R}_{\mathrm{r}}=\left(\varepsilon_{\text {unload }}-\varepsilon_{\text {rec }}\right) / \varepsilon_{\text {unload }} \times 100 \%
\end{aligned}
$$

In order to perform visual shape memory test, specimens with a permanent straight bar shape were deformed to a temporary $\mathrm{U}$ shape in an oil bath at $\mathrm{T}_{\mathrm{g}}$, holded for a controlled exposure time, and then, cooled in a water bath at ambient temperature to fix the temporary shape. The specimen with the temporary fixed shape was then placed back in hot oil to trigger the shape recovery and recovery angle. Deviation from initial straight shape $\left(0^{\circ}\right)$ was measured.

Water absorption test were also performed. First, the specimens (15 mm x $45 \mathrm{~mm}$ x (1-2) $\mathrm{mm}$ ) were dried in an oven at $150{ }^{\circ} \mathrm{C}$ until constant weight was registered. Epoxy specimens were inmersed in a water bath at $20^{\circ} \mathrm{C}$ and periodically samples were weighted during 11 days. Since the samples did not reach the equilibrium, the temperature was raised to $80^{\circ} \mathrm{C}$ and the water absortion was registered for 50 days. After this time, the samples were dried and $T_{g}$ was measured and compared to pristine $T_{g}$ to evaluate the degradation of the network.

\section{Results and discussion}

\section{Synthesis of aromatic disulfide based epoxy vitrimers}

Five dynamic networks with different molar percentages of diepoxides (DGEBA/DGEPPG) were synthesized: E100 (100/0), E75 (75/25), E50 (50/50), E25 (25/75) and E0 (0/100). The chemical structures of the reactants and the formulation of each system are shown in Figure 1 and Table 1, respectively. In all the formulations 1.1 equivalent of AFD was used per 1.0 epoxy equivalent. Additionally, R100 thermoset was 
synthesized for comparative purposes starting from DGEBA and D-230. The epoxy networks were prepared by mixing the epoxy monomers and the hardener followed by a curing cycle at high temperatures. The complete curing of the networks was confirmed by the lack of residual exothermic peak at the first scan of the DSC thermogram. Additionally, the complete curing was assessed by FTIR (ESI Figure 1) following the criteria of the disappearance of the epoxy functional group at $915 \mathrm{~cm}^{-1}$ (C-O stretching) and $3056 \mathrm{~cm}^{-1}(\mathrm{C}-\mathrm{H}$ stretching), as well as the increase of the peak at $3370 \mathrm{~cm}^{-1}$ attributed to the new hydroxyl group generated upon the oxirane opening.

\section{Thermal and thermo-mechanical characterization}

Thermal properties of the epoxy networks depend on compositional and structural factors such as stiffness of polymer segments, interchain cohesive forces and crosslinking. The flexibility and length of the molecular segments differ considerably within the E series, and thus, distinct thermal and mechanical properties are expected. TGA, DSC and DMA techniques were used to measure thermal stability and $\mathrm{T}_{\mathrm{g}}$ temperatures (Table 2).

Table 1: Thermal decomposition and glass transition temperatures.

\begin{tabular}{l|ccc}
\hline Ref. & $\mathbf{T}_{\text {onset }}{ }^{\text {TGA }}\left({ }^{\circ} \mathbf{C}\right)$ & $\mathbf{T}_{\mathbf{g}}{ }^{\text {DSC }}\left({ }^{\circ} \mathbf{C}\right)$ & $\mathbf{T}_{\mathbf{g}}{ }^{\text {DMA }}\left({ }^{\circ} \mathbf{C}\right)$ \\
\hline R100 & 319 & 70 & 77 \\
E100 & 290 & 140 & 142 \\
E75 & 271 & 105 & 114 \\
E50 & 263 & 75 & 88 \\
E25 & 258 & 56 & 66 \\
E0 & 200 & 39 & 44 \\
\hline
\end{tabular}

All DSC thermograms displayed a single thermal transition in the experimental temperature range which was attributed to the $T_{g}$ (Figure 2a). The incorporation of a flexible monomer lowered $T_{g}$ values [30]. Such thermogram profiles also proved that the networks had an homogeneous phase structure. The $\mathrm{T}_{\mathrm{g}}$ was also determined from the peak of $\tan \delta$ recorded in the temperature ramp DMA tests (Figure 3a). There is almost a linear relationship between the ratio of epoxy monomers and their $\mathrm{T}_{\mathrm{g}}$ (Figure 2c). Thus, any network with the desired $\mathrm{T}_{\mathrm{g}}$ value $\left(\mathrm{T}_{\mathrm{g}}{ }^{\mathrm{DSC}}\right.$ between $142{ }^{\circ} \mathrm{C}$ and $39^{\circ} \mathrm{C}$ ) could be formulated. In practice, in order to employ ambient temperature as shape fixing temperature and avoid undesired flow and stress relaxation, materials should have sufficiently high $\mathrm{T}_{\mathrm{g}}$. 
a)

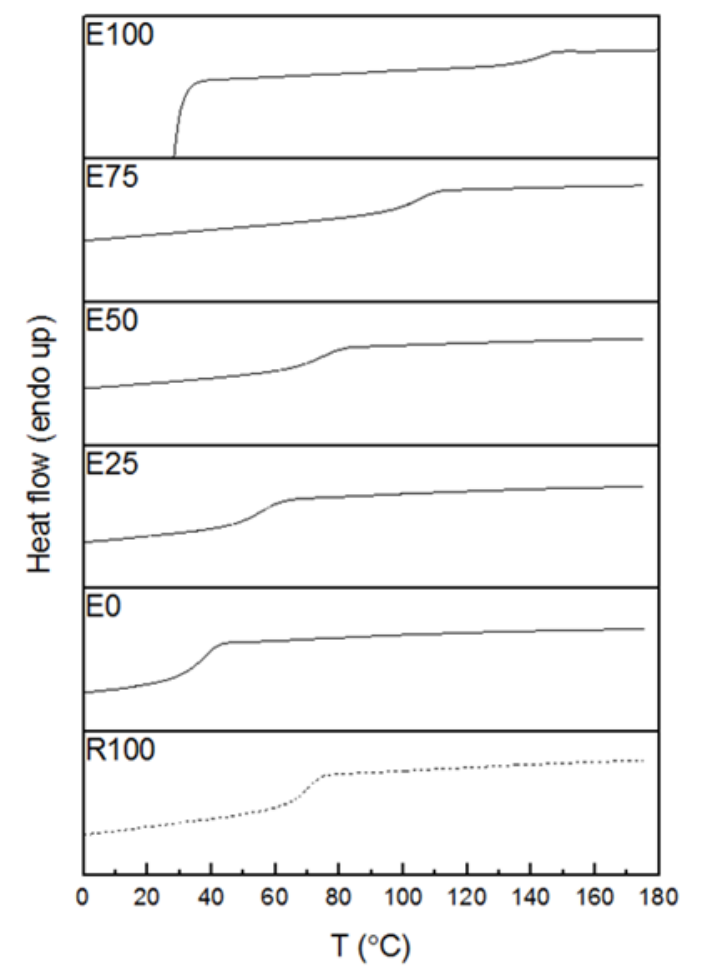

b)

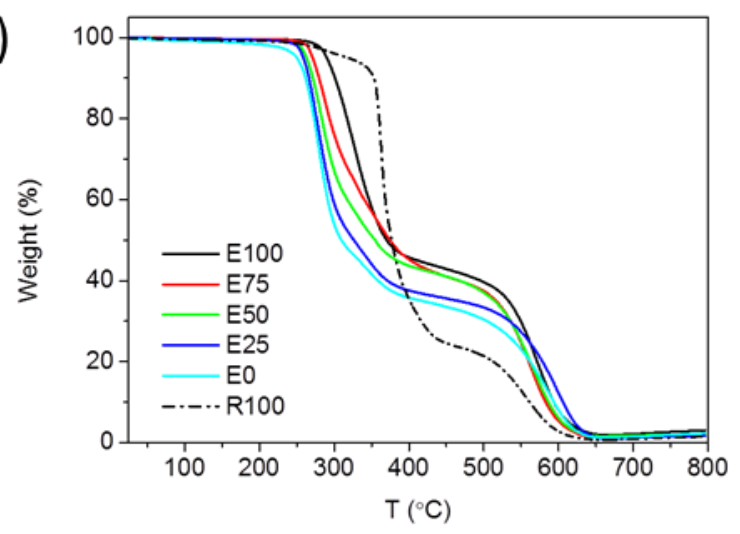

c)

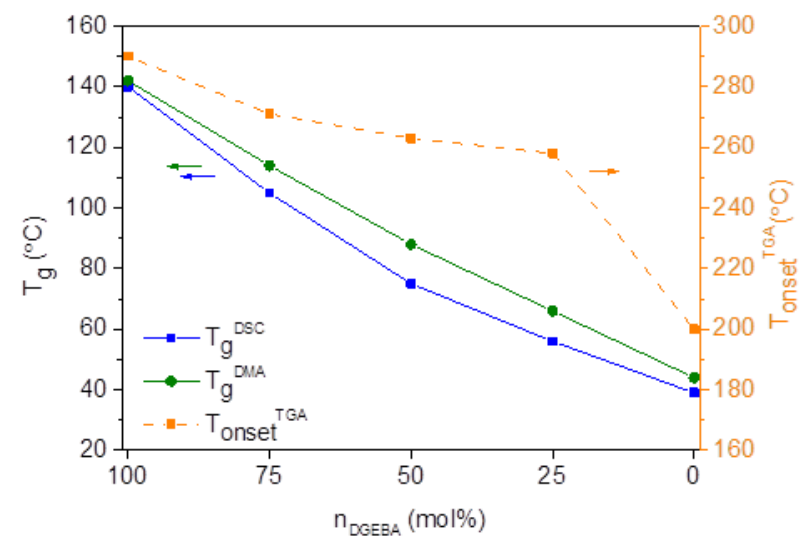

Figure 2: Thermal characterization of networks: a) DSC thermograms. b) TGA thermograms in air. c) Graphical representation of $\mathrm{T}_{\mathrm{g}} \mathrm{s}$ measured by DSC and DMA and $\mathrm{T}_{\text {onset }}{ }^{\text {TGA }}$ measured by TGA of E series networks.

The thermal stability of the networks in air was evaluated by thermogravimetric analysis (Figure $2 \mathrm{~b}$ ). Two observations were evident: (i) all epoxy networks decomposed in two apparent steps, and (ii) the onset 
temperature, $\mathrm{T}_{\text {onset }}{ }^{\mathrm{TGA}}$ (i.e. the temperature of $5 \mathrm{wt} \%$ loss of material), was shifted to lower temperatures with increasing percentage of DGEPPG in the formulation. The registered $\mathrm{T}_{\text {onset }}{ }^{\mathrm{TGA}}$ values differed quantitatively from $290{ }^{\circ} \mathrm{C}$ of E100 to $200{ }^{\circ} \mathrm{C}$ of E0 (Table 2 and Figure 2c). This is explained because rigid aromatic segments of DGEBA provide better thermal stability compared to flexible polyether chains [31]. Thus networks of E series that contain more DGEBA are thermally more stable, and that the lack of it lowers considerably the $\mathrm{T}_{\text {onset }}{ }^{\text {TGA }}$. Additional isothermal tests were carried out with E75, E50 and E25 samples to simulate extreme reprocessing (permanent shape modification) conditions (ESI Figure 2). At $200{ }^{\circ} \mathrm{C}$ for 30 minutes under air, samples showed no-significant weight loss (0.66-1.25 wt $\%)$ and no structural degradation was evidenced since $T_{g}$ values measured after the tests were in accordance with $T_{g} s$ of pristine materials. R100 sample showed the highest $\mathrm{T}_{\text {onset }}{ }^{\text {TGA }}$ among all samples. This is attributed to the lack of the weak disulfide moieties which lower the overall thermal stability of the E series epoxy matrices.

a)

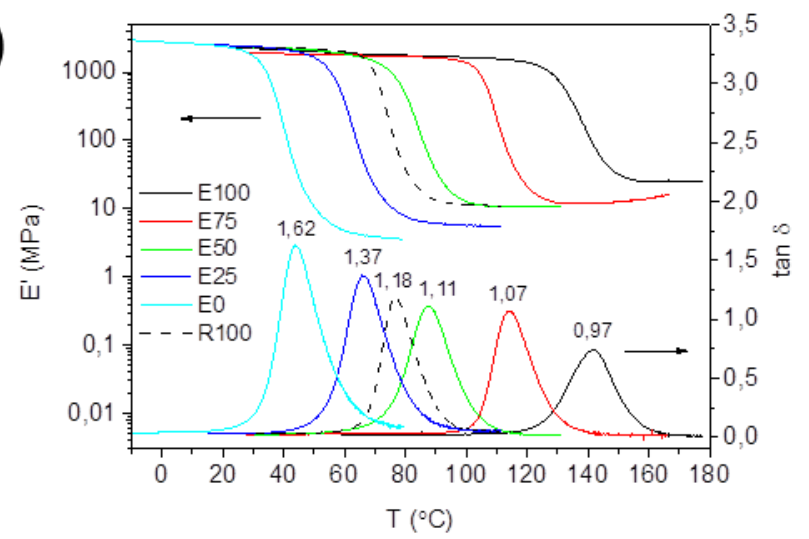

b)

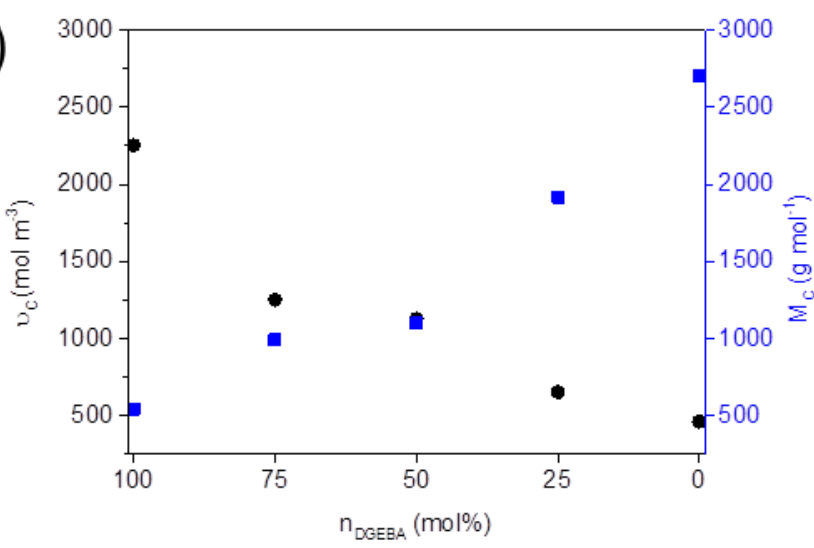

Figure 3: a) Temperature dependence of storage modulus (E') and $\tan \delta$ of the epoxy networks. b) Calculated crosslink density $\left(v_{\mathrm{C}}\right)$ and molecular weight between crosslinks $(\mathrm{Mc})$ of E series applying rubber elasticity theory.

The temperature ramp DMA test provides information about the relative contribution of viscous and elastic properties of the materials in the analyzed temperature range, i.e. storage modulus (E'), loss modulus (E') and $\tan \delta$ which is the ratio of E' to E'. The height of $\tan \delta$ indicates the energy dissipation potential of the material; and in general, the higher the $\tan \delta$ value, the better are the damping properties. In the $\mathrm{E}$ series the maximun $\tan \delta$ values range between 0.97-1.62, corresponding to lower and higher DGEPPG flexible segment concentration in the network (Figure 3a). 
The weigth percentage of the dynamic hardener in the networks fall in the range of 29-27 wt $\%$ corresponding to E100 and E0, respectively. This is because diepoxy monomers have similar epoxy equivalent weight (EEW), $170 \mathrm{~g} \mathrm{eq}^{-1}$ DGEBA and $190 \mathrm{~g} \mathrm{eq}^{-1}$ DGEPPG, and all were formulated with 1.1 equivalent of AFD. Additionally, the densities of the networks are between $1.22 \mathrm{~g} \mathrm{ml}^{-1}$ and $1.25 \mathrm{~g} \mathrm{ml}^{-1}$. Thus, it can be concluded that the disulfide juncture concentration is similar in the whole E series. However, the two diepoxy monomers differ in the chain length and flexibility which certainly leads to completely different network structures. DGEBA has a rigid aromatic backbone, whereas DGEPPG provides a flexible polyether segment. The crosslink density $\left(v_{\mathrm{C}}\right)$ provides an idea of the network structure which is defined as the number of elastically effective network chains per unit volume of the sample. For an amorphous thermoset, $v_{\mathrm{C}}$ can be experimentally obtained applying the rubber elasticity theory above its $\mathrm{T}_{\mathrm{g}}$ (Eq.3).

$$
\mathrm{v}_{\mathrm{C}}=\mathrm{E}^{\prime} / 3 \cdot \mathrm{A} \cdot \mathrm{R} \mathrm{T} \quad \text { (Eq. 3) }
$$

where $\mathrm{E}^{\prime}$ is measured in the rubbery plateau $\left(30^{\circ} \mathrm{C}\right.$ above $\left.\mathrm{T}_{\mathrm{g}}{ }^{\mathrm{DMA}}\right)$; $\mathrm{A}$ is the front factor often assumed to be unity; $\mathrm{R}$ is the gas constant $\left(8.314 \mathrm{~J} \mathrm{~mol}^{-1} \mathrm{~K}^{-1}\right)$ and $\mathrm{T}$ is equal to $\mathrm{T}_{\mathrm{g}}{ }^{\mathrm{DMA}}+30 \mathrm{~K}$. The $v_{\mathrm{C}}$ can be also described in terms of average molecular weight between crosslinks $\left(\mathrm{M}_{\mathrm{C}}\right)$ (Eq. 4).

$$
\mathrm{M}_{\mathrm{C}}=\mathrm{d} / v_{\mathrm{C}}
$$

where $\mathrm{d}$ is the cured resin density.

\begin{tabular}{|c|c|c|c|c|c|c|c|c|}
\hline \multirow{2}{*}{ Ref. } & \multirow{2}{*}{$\begin{array}{l}\text { Tan } \delta \\
\max .\end{array}$} & \multirow{2}{*}{$\begin{array}{l}E^{\prime}\left(10^{6} \text { Pa }\right) \text { at } \\
T_{g}{ }^{\text {DMA }}+30 \mathrm{~K}\end{array}$} & \multirow{2}{*}{$\begin{array}{c}d \\
\left(10^{6} \mathrm{gm}^{-3}\right)\end{array}$} & \multirow{2}{*}{$\begin{array}{c}\mathbf{v}_{\mathrm{C}} \\
\left(\mathrm{molm}^{-3}\right)\end{array}$} & \multirow{2}{*}{$\begin{array}{c}\mathbf{M}_{\mathrm{C}} \\
\left(\mathrm{gmol}^{-1}\right)\end{array}$} & \multirow{2}{*}{$\begin{array}{c}\text { Swelling }^{1} \\
(\%)\end{array}$} & \multicolumn{2}{|c|}{ Water uptake $^{2}(\%)$} \\
\hline & & & & & & & $20^{\circ} \mathrm{C}$ & $80^{\circ} \mathrm{C}$ \\
\hline $\mathbf{R 1 0 0}$ & 1.18 & 11 & 1.15 & 1161 & 990 & $-3^{3}$ & $-3^{3}$ & $-3^{3}$ \\
\hline E100 & 0.97 & 25 & 1.22 & 2252 & 542 & 4.2 & 0.85 & 2.9 \\
\hline E75 & 1.08 & 13 & 1.24 & 1250 & 992 & 17.9 & 0.66 & 3.8 \\
\hline E50 & 1.11 & 11 & 1.24 & 1128 & 1099 & 30.8 & 0.74 & 10.4 \\
\hline E25 & 1.37 & 6 & 1.25 & 652 & 1917 & 33.3 & 1.81 & 35.1 \\
\hline E0 & 1.62 & 4 & 1.25 & 462 & 2706 & 40.3 & 2.92 & 53.7 \\
\hline
\end{tabular}

Table 3: Density, $v_{C}$ and $M_{C}$ of the networks applying rubber elasticity theory.

${ }^{1}$ Weight gain in acetone in equilibrium. ${ }^{2}$ Equilibiurm not reached after 11 days at $20{ }^{\circ} \mathrm{C}$ and after 50 days at $80{ }^{\circ} \mathrm{C} .{ }^{3}$ Not measured.

The difference between the composition of R100 and E100 is the diamine hardener (D230 and AFD, respectively), since in both formulations the epoxy monomer is DGEBA. R100 contains the flexible and long D-230 whereas E100 contains the short aromatic AFD. The difference in crosslinking density, i.e. 100 showing higher crosslinking density than R100, is attributed to those structural differences. As expected, within the E series, replacing DGEBA by the flexible DGEPPG monomer (presenting same main chain that D-230) leads to substantial decrease of $v_{C}$ and associated increase of $M_{C}$ (Table 3). The measured data shows that crosslinking density of R100 and E75/E50 are comparable and this is attributed to a similar balance of flexible and rigid segments.

These calculations are experimentally supported by the results of equilibrium swelling tests in an organic solvent since swelling is closely related to crosslinking density (Table 3). To do so samples were submerged in acetone and weight gain was monitored until equilibrium was reached. The solvent gain is in line with the capability of expansion of the network, the lower the crosslinking density, the higher the swelling capability. 
Another important structural difference among the networks are their polarity and water absortion capability. Epoxy matrices easily absorb water when exposed to humid environments due to polar hydroxyl groups. The extent of water absorption is further enhanced by the polarity of the matrix and its swelling capability. In this series, both variables point in the same direction due to highly hydrophilic and flexible polyether DGEPPG segments. To assess this (ESI Figure 3), specimens were immersed in water at ambient temperature (ca 20 ${ }^{\circ} \mathrm{C}$ ), and the weight gain was monitored for eleven days. During this period of time samples did not reach equilibrium: the larger uptake was for E0 (2.92 wt\%) followed by E25 (1.81 wt\%); the rest of the samples showed smaller weight gain (0.66-0.86 wt\%). Aiming at accelerating the absorption and highlight the structural differences, the temperature was raised up to $80{ }^{\circ} \mathrm{C}$ and the weight gain was monitored. Ater 50 days, only E100 (2.9 wt\%) and E75 (3.8 wt\%) reached the plateau; E50 (10.4 wt\%), E25 (35.1 wt\%) and E0

(53.7 wt $\%$ ) showed an upward trend. After this time samples were dried and $\mathrm{T}_{\mathrm{g}}{ }^{\mathrm{DSC}}$ of the materials were measured to assess any structural damage (i.e hydrothermal degradation) (ESI Figure 4 and ESI Table 1). The $\mathrm{T}_{\mathrm{g}} \mathrm{s}$ measured by DSC were in line with starting values. The high water uptake of the samples evidenced their high susceptibility to plasticization under humidity conditions which has a dramatic effect on lowering $\mathrm{T}_{\mathrm{g}}$ and affecting mechanical (lowering modulus) and shape memory properties.

\section{Stress relaxation and creep tests}

Vitrimers based on aromatic disulfide crosslinks undergo associative type exchange [32-33]. Applying pressure and temperatures above $\mathrm{T}_{\mathrm{g}}$ and $\mathrm{T}_{\mathrm{v}}$, materials can be reprocessed into new shape albeit their crosslink structure. Small pieces of cured dynamic epoxies were reprocessed into flat homogeneous thin sheets (ESI Figure 5). For comparative purposes, the same compression was applied to R100 which showed no malleability and reprocessing capability, and showed multiple cracks.

Then, stress relaxation of the networks was investigated in the rheometer applying shear deformations and monitoring the stress (ESI Figure 7). Relaxation time $\left(\tau^{*}\right)$ was calculated following the Maxwell model which defines it as the time needed for the modulus to decrease to $37 \%$ of its initial value $\left(\mathrm{G} / \mathrm{G}_{0}=1 / \mathrm{e}\right)$. $\tau^{*}$ data as a function of the temperature follows the Arrhenius' law (Eq. 5) and the corresponding plots are shown in Figure 4.

$$
\tau(T)=\tau_{0} e^{\left(\frac{E a}{R T}\right)}
$$

where $\tau$ is the relaxation time at each temperature, Ea is the activation energy, $\mathrm{R}$ is the gas constant (8.314 $\mathrm{J}$ $\mathrm{mol}^{-1} \mathrm{~K}^{-1}$ ) and $\mathrm{T}$ is the absolute temperature. 

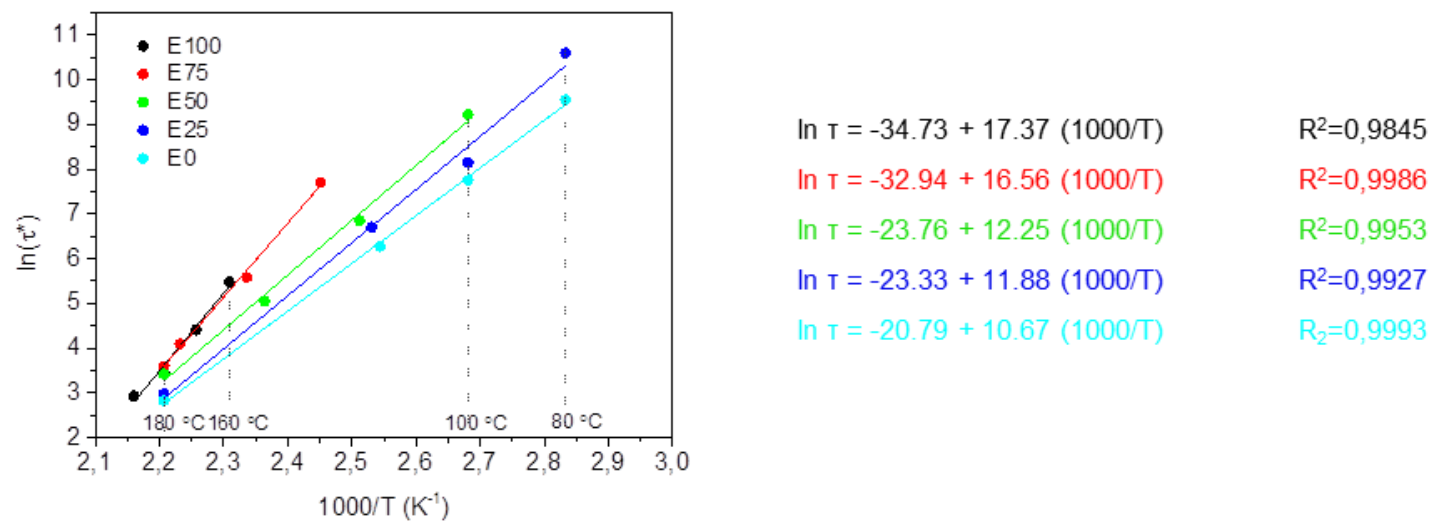

Figure 4: Fitting of the relaxation times to the Arrhenius's equation.

Two conclusions were drawn from Figure 4: i) When comparing all the networks at a given temperature (T > $\mathrm{T}_{\mathrm{g}}$ and $\mathrm{T}_{\mathrm{v}}$ ); the lower the $\mathrm{T}_{\mathrm{g}}$, the shorter the relaxation time of the network. This is attributed to the enhanced diffusion and exchange of reactive groups due to its lower crosslinking density and viscosity. ii) The higher the $\mathrm{T}_{\mathrm{g}}$ of the network, the higher the Ea. This points out that the rate of exchange reaction has higher thermal dependency, i.e. a small thermal variation leads to bigger structural changes. In Table $4 \mathrm{Ea}$ and interpolated $\tau$ values at various temperatures $\left(180{ }^{\circ} \mathrm{C}\right.$ and $\left.\mathrm{T}_{\mathrm{g}}{ }^{\mathrm{DMA}}+50{ }^{\circ} \mathrm{C}\right)$ for each network are given. The Ea values could be grouped into two value sets: ca $140 \mathrm{KJ} \mathrm{mol}^{-1}$ (E100 and E75) and ca $100 \mathrm{KJ} \mathrm{mol}^{-1}$ (E50 and E25, slightly lower E0). The first set shows that small increase in temperature leads to a more pronounced reduction of $\tau$ compared to formulations from the second set. All plot lines converged at high temperature (e.g. the $\tau$ values of all networks are of the same order of magnitude at $180{ }^{\circ} \mathrm{C}$ ), showing that the rate of exchange is not limited by viscosity anymore. The $\tau$ of each network at $\mathrm{T}_{\mathrm{g}}+50{ }^{\circ} \mathrm{C}$ differ substantially (3 orders of magnitude): for E100 it takes less than $20 \mathrm{~s}$ and for E0 1 hours. This is explained by the distinct mobility and kinetic energy that the systems own in each case to promote the disulfide exchange and polymer chain movements. The fact that the dynamic properties of vitrimers are highly influenced that the exact composition and architecture of the matrix has been previously observed [9].

Table 4: Ea, $\mathrm{T}_{\mathrm{g}}{ }^{\mathrm{DMA}}, \mathrm{T}_{\mathrm{v}}$ and $\tau$ at various temperatureas $\left(180{ }^{\circ} \mathrm{C}, \mathrm{T}_{\mathrm{g}}+50{ }^{\circ} \mathrm{C}\right.$ and $\left.\mathrm{T}_{\mathrm{v}}+50{ }^{\circ} \mathrm{C}\right)$ of networks.

\begin{tabular}{|c|c|c|c|c|c|c|}
\hline \multirow{2}{*}{ Ref } & \multirow{2}{*}{$\begin{array}{c}\text { Ea } \\
\left(\mathrm{KJ} \mathrm{mol}^{-1}\right)\end{array}$} & \multicolumn{2}{|c|}{$\tau^{*}(\mathrm{~s})$ at } & \multirow{2}{*}{$\begin{array}{c}\mathbf{T}_{\mathrm{g}}^{\text {DMA }} \\
\left({ }^{\circ} \mathbf{C}\right)\end{array}$} & \multirow[t]{2}{*}{$\mathbf{T}_{\mathbf{v}}\left({ }^{\circ} \mathbf{C}\right)$} & \multirow{2}{*}{$\begin{array}{c}\Delta \mathrm{TT} \\
\left(\mathbf{T}_{\mathrm{g}}^{\mathrm{DMA}}-\mathrm{T}_{\mathrm{v}}\right)\end{array}$} \\
\hline & & $180^{\circ} \mathrm{C}$ & $\mathrm{T}_{\mathrm{g}}+\mathbf{5 0}{ }^{\circ} \mathrm{C}$ & & & \\
\hline E100 & 144.4 & 37 & $14\left(192{ }^{\circ} \mathrm{C}\right)$ & 142 & 101 & 41 \\
\hline E75 & 137.6 & 37 & $312\left(155^{\circ} \mathrm{C}\right)$ & 114 & 95 & 19 \\
\hline E50 & 101.8 & 26 & $953\left(127^{\circ} \mathrm{C}\right)$ & 77 & 65 & 12 \\
\hline E25 & 98.7 & 18 & $1337\left(116^{\circ} \mathrm{C}\right)$ & 66 & 53 & 13 \\
\hline E0 & 88.7 & 16 & $3698\left(95^{\circ} \mathrm{C}\right)$ & 45 & 38 & 7 \\
\hline
\end{tabular}

Additionaly, $\mathrm{T}_{\mathrm{v}}$ was determined from Arrhenius' fitted line using a relaxation time calculated from the

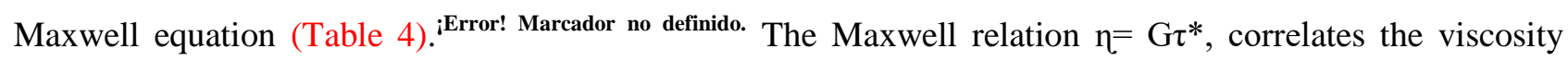
$\left(\eta=10^{12} \mathrm{~Pa} s\right)$ with relaxation time, $\mathrm{G}$ being the shear modulus. $\mathrm{G}$ was calculated from the tensile modulus (E') as measured by DMA from the relation $G^{\prime}=E^{\prime} / 2(1+v)$; with $v=0.5$, the Poisson ratio usually used for rubbers (ESI Table 2). The calculated $\mathrm{T}_{\mathrm{v}}$ temperatures were lower than the corresponding $\mathrm{T}_{\mathrm{g}}$, showing that as soon as intermolecular forces are overcome and molecular motion is gained, the exchange reaction takes 
place. The temperatures at which disulfide exchange reactions occur are extremely sensitive to the molecular structure and the $T_{g}$ of the vitrimer. The thermal difference $\left(T_{g}{ }^{\text {DMA }}-T_{v}\right)$ was enhanced with increasing the $T_{g}$ of the network.

Additional creep experiments at various temperatures were performed to compare the distinct behavior of a vitrimer and a thermoset without dyanamic bonds (Figure 5). To do that E50 network was selected and compared to R100 in 30 minute tests at four temperatures. Albeit not being structurally analogues, both networks are composed of aromatic and PPG segments, and present comparable $\mathrm{T}_{\mathrm{g}}{ }^{\text {DMA }}$ and $\mathrm{v}_{\mathrm{C}}$ values.
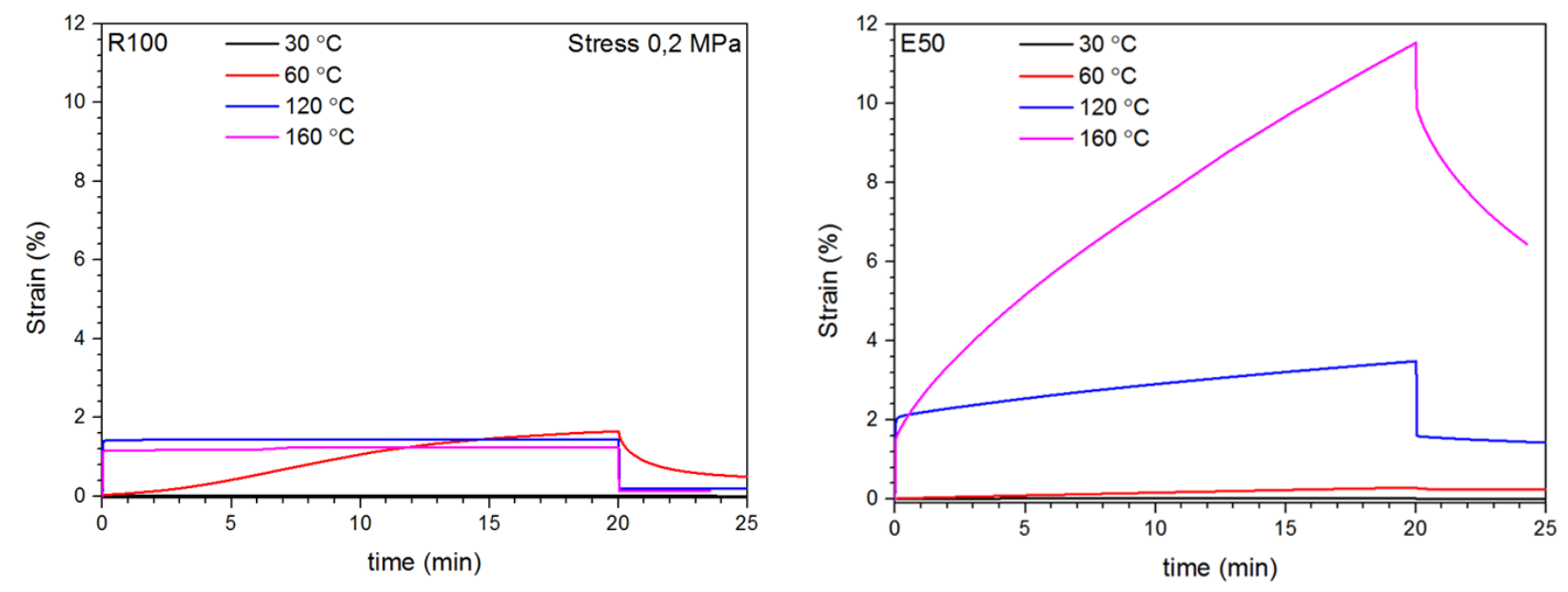

Figure 5: Creep experiment of R100 $\left(\mathrm{T}_{\mathrm{g}}{ }^{\mathrm{DMA}}=77^{\circ} \mathrm{C}\right)$ and $\mathrm{E} 50\left(\mathrm{~T}_{\mathrm{g}}{ }^{\mathrm{DMA}}=88^{\circ} \mathrm{C}\right)$ at $30^{\circ} \mathrm{C}, 60^{\circ} \mathrm{C}, 120^{\circ} \mathrm{C}$ and $160{ }^{\circ} \mathrm{C}$.

At $30{ }^{\circ} \mathrm{C}$ neather of the networks presented a deformation under $0.2 \mathrm{MPa}$ stress. $\mathrm{R} 100\left(\mathrm{~T}_{\mathrm{g}}{ }^{\mathrm{DMA}}=77^{\circ} \mathrm{C}\right)$ strained around $1.75 \%$ at $60{ }^{\circ} \mathrm{C}, 120{ }^{\circ} \mathrm{C}$ and $160{ }^{\circ} \mathrm{C}$ to accommodate the applied stress. At temperatures well above the $\mathrm{T}_{\mathrm{g}}$ the network was stretched instantly, and the the recovery of the elastic deformation also occurred right away. At $60{ }^{\circ} \mathrm{C}$, both processes were progressive, most likely because the network was below $\mathrm{T}_{\mathrm{g}}$ and the intermolecular interactions caused resistance. On the other hand, $\mathrm{E} 50\left(\mathrm{~T}_{\mathrm{g}}{ }^{\mathrm{DMA}}=88{ }^{\circ} \mathrm{C}\right)$ presented negliable creep at $60{ }^{\circ} \mathrm{C}$, but at $120^{\circ} \mathrm{C}$ and $160{ }^{\circ} \mathrm{C}$ the strain increaseed rapidly with increasing temperature. This clearly indicates that the network can release the stress by continuous rearrangement of the network, overcoming the limits of the fixed network structure. Regarding the recovery, it was observed that the system first showed a partial instanteneous recovery followed a slower rate process. The deformation was not recovered quantitatively due the relaxation of the network.

\section{Shape memory tests}

The sharp drop in modulus and extended rubbery plateau observed in the temperature sweep in DMA are properties highly recommended for SMP materials. First, the shape memory properties were analyzed by visual experiment. The test was designed to compare shape recovery of E75, E50 and E25 networks when distinct exposure times ( $0 \mathrm{~min}, 1 \mathrm{~min}, 10 \mathrm{~min}, 1 \mathrm{~h}$ and $3 \mathrm{~h}$ ) were set at the corresponding shape programming step (Figure 6). The tests were performed at $\mathrm{T}_{\text {trans }}$ corresponding to $\mathrm{T}_{\mathrm{g}}{ }^{\mathrm{DSC}}$ of each network $\left(105{ }^{\circ} \mathrm{C}\right.$ for E75, $77^{\circ} \mathrm{C}$ for E50 and $57{ }^{\circ} \mathrm{C}$ for E25). Before the tests, one edge of each rectangular shape samples was covered with tape to avoid adhesion between network surfaces during the tests. For each experiment, a pristine rectangular shape specimen was heated to $\mathrm{T}_{\text {trans }}$ inside an oil bath, deformed into a closed $\mathrm{U}$ shape and holded 
with a binder clip for different time lapses. Then, the specimen was cooled down to ambient temperature in a water bath and the binder clip was removed. Finally, the samples were immersed in the oil bath at $\mathrm{T}_{\text {trans }}$ and the shape recovery was determined by measuring the deformation angle. We assumed that if there was no stress relaxation the sample would have the potential of recovering the initial flat rectangular shape $\left(0^{\circ}\right.$ deformation angle, $100 \%$ recovery). In case complete stress relaxation occurred the specimen would fix the $\mathrm{U}$ shape $\left(180^{\circ}\right.$ deformation, $0 \%$ recovery). At 0 min test all the networks recovered the initial permanent shape whereas at 3 hour tests the deformation were pronounced as expected. When it came to compare the three networks, the deformation associated to the stress relaxation was more evident for E75, followed by E50 and E25. The relaxation times associated to these temperatures were not experimentally measured and should have to be extrapolated from the stress relaxation test results (Figure 4). In any case, the enhanced stress relaxation of E75 could be attributed to a faster exchange reaction activated by the higher temperature.

Step 1: Shape programming
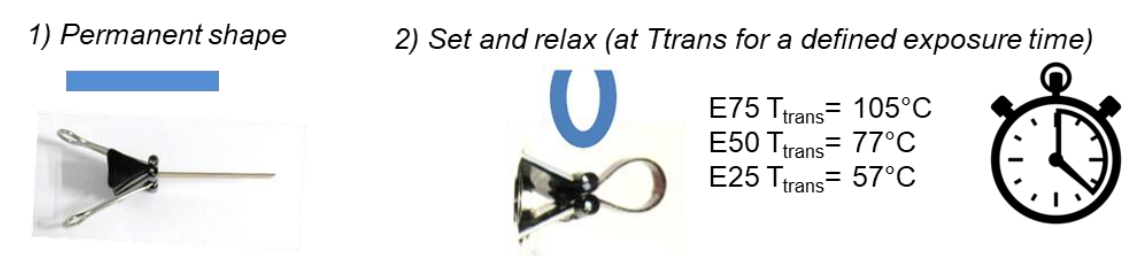

3) Fix temporary shape at it

Step 2: Recovered shapes of E75, E50 and E25 at $T_{\text {trans }}$ treated under different exposure times:

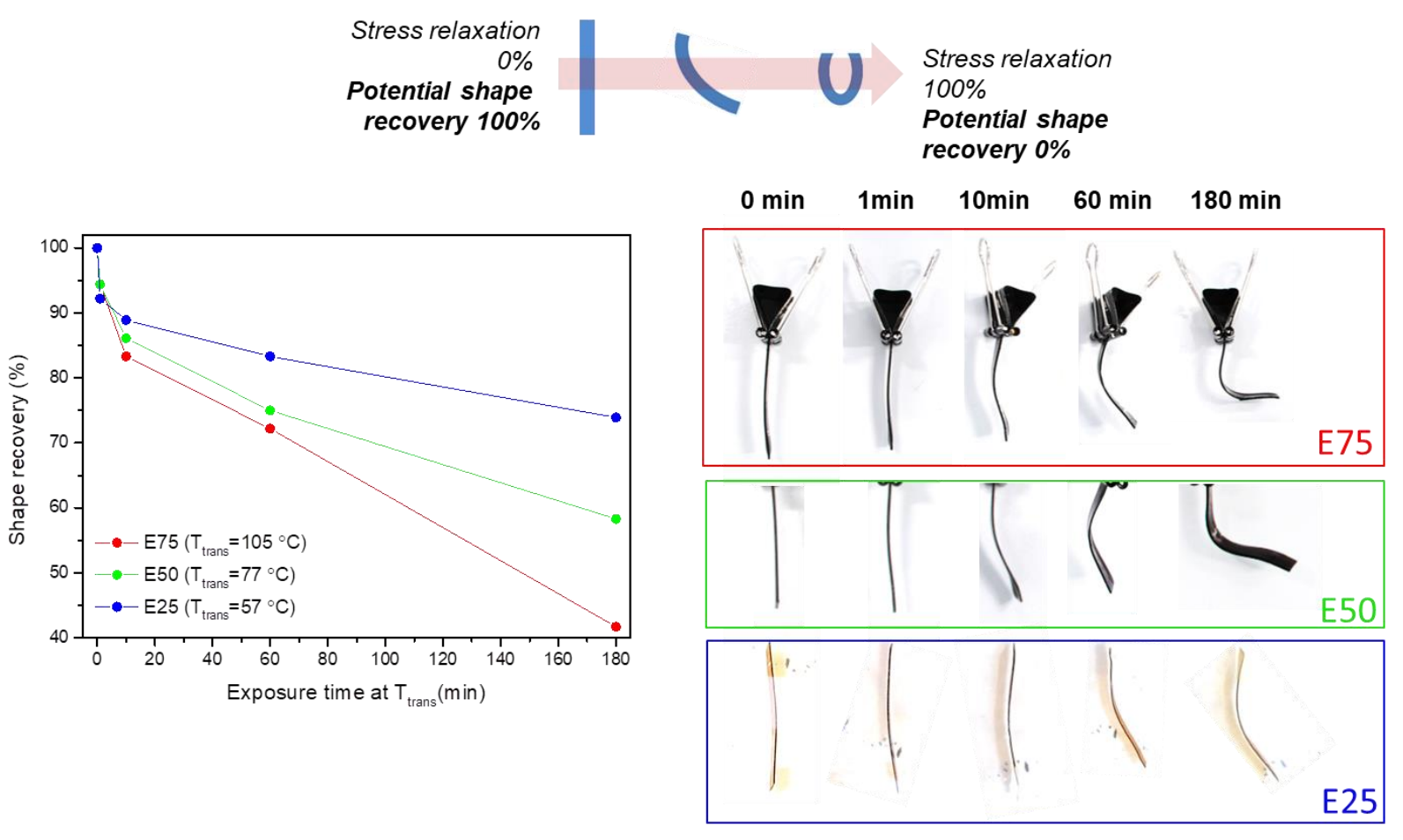

Figure 6: Visual shape memory tests of E75, E50 and E25.

E25 network was selected to carry out quantitative thermo-mechanical cyclic tests in DMA in force controlled mode equipped with a GCA and tensile fixture to analyse the effect on $\operatorname{Rf}(\%)$ and $\operatorname{Rr}(\%)$ of two parameters, i.e. the exposure time at $\mathrm{T}_{\text {trans }}$ and the selected $\mathrm{T}_{\text {trans }}$. Rf shows the ability of the material to fix the strain imposed on it after cooling and unloading the sample. It is also affected by the expansion coefficient of 
the resin which have not been determined in this work. On the other hand, Rr reflects the percentage of the initial strain that is recovered after the thermo-mechanical cycle. If the system recovers the initial strain in the "permanent shape" after re-heating the sample in the temporary shape, the $\mathrm{Rr}$ is $100 \%$. The tests were carried out following the procedure described in the characterization techniques section and measured strain values are provided in ESI Table 3.

\section{a) Exposure time 0 min}

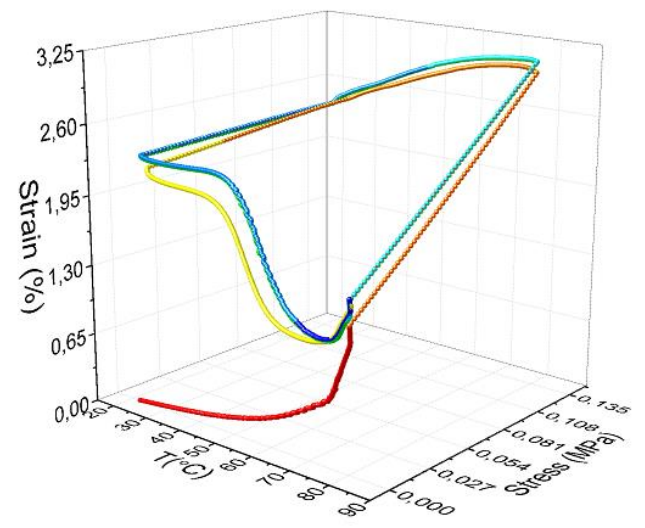

b) Exposure time $15 \mathrm{~min}$

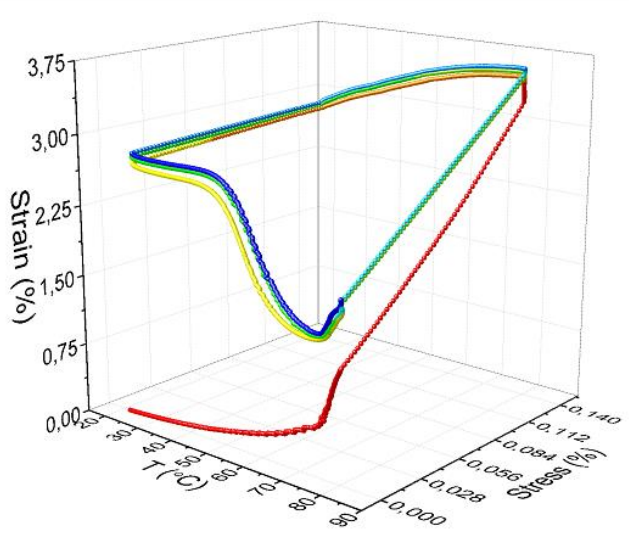

\section{c) Exposure time $30 \mathrm{~min}$}

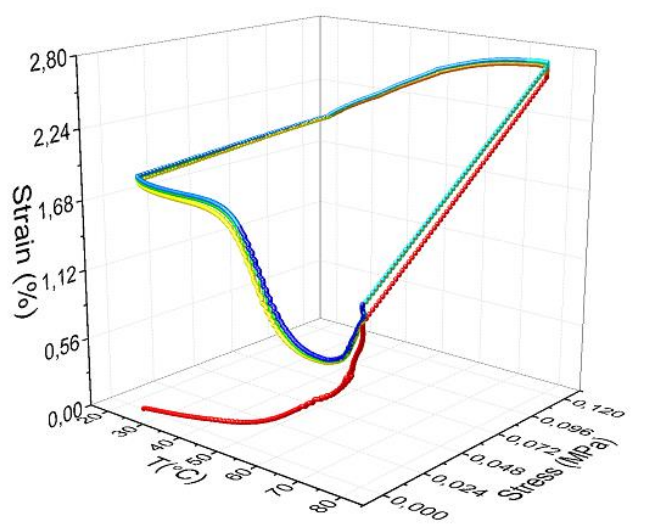

Figure 7: Thermo mechanical cycles of E25 recorded setting different exposure times at $\mathrm{T}_{\text {trans }}\left(80^{\circ} \mathrm{C}\right)$ : a) 0 min, b) $15 \mathrm{~min}$ and c) $30 \mathrm{~min}$. Trajectory color coded for time: from red ( $\mathrm{t}=0 \mathrm{~s})$ to dark blue.

In order to study the effect of the exposure time at $\mathrm{T}_{\text {trans }}$ on the shape memory properties of E25 three experiments were carried out (Figure 7). $\mathrm{T}_{\text {trans }}$ was set at $80{ }^{\circ} \mathrm{C}$ and different exposure times $(0 \mathrm{~min}, 15 \mathrm{~min}$ 
and $30 \mathrm{~min}$ ) were screened. It was observed that in the first thermo-mechanical cycle there was a major deformation that was not recoverable. This was attributed to the unrecoverable plastic deformation (e.g. uncoiling along stress axis) that is induced in cycle 1 . In the subsequent cycles 2 and 3, the trajectories were overlapped. In Figure 9a the calculated $\mathrm{Rr}$ and $\mathrm{Rf}$ are provided. The $\mathrm{Rr}$ of the fist cycle was around 50\% in the tested temperatures, and in the subsequent cycles, the value showed a decreasing trend from almost $100 \%$ to $90 \%$. Rf values obtained at different exposure times falled within $70-80 \%$ with no particular trend and could be likely be caused by thermal shrinkage of the matrices. It was concluded that at $80{ }^{\circ} \mathrm{C}$ the stress relaxation is slow and thus, exposure time has no significant effect on the shape recovery.

a) $\operatorname{Ttrans}=80^{\circ} \mathrm{C}$

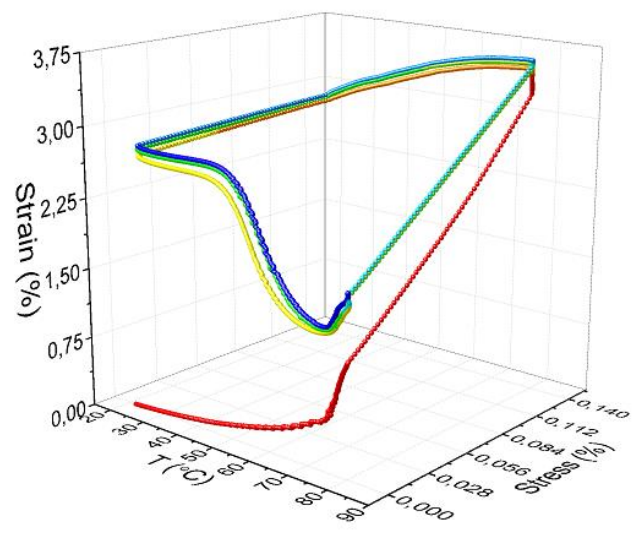

c) Ttrans $=120^{\circ} \mathrm{C}$

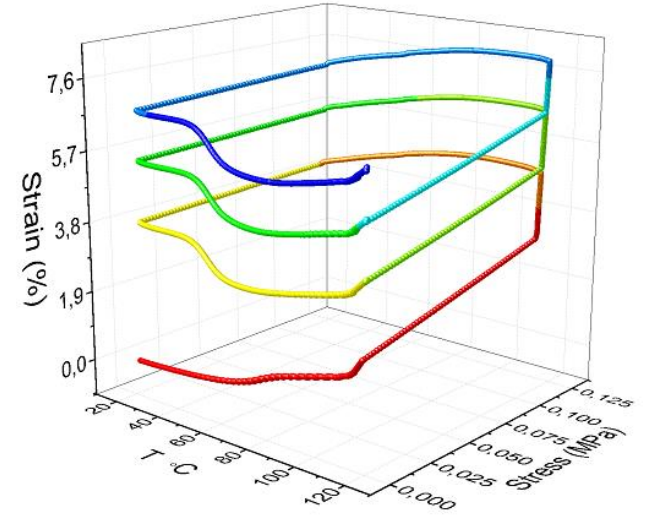

b) $\operatorname{Trans}=100^{\circ} \mathrm{C}$

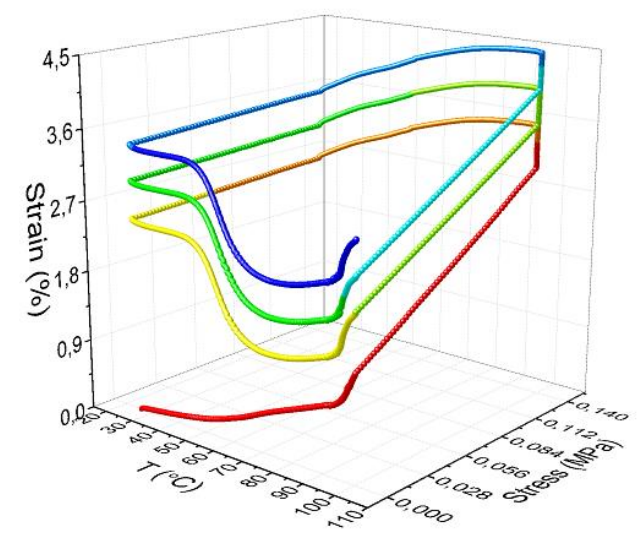

d) $\operatorname{Ttrans}=140{ }^{\circ} \mathrm{C}$

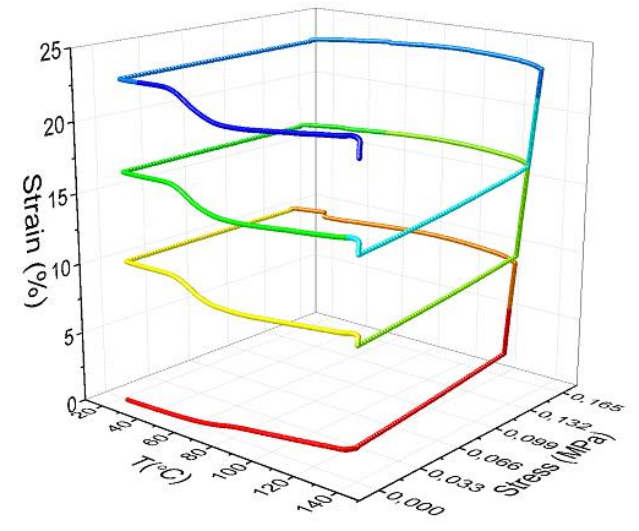

Figure 8: Thermo mechanical cycles of E25 recorded setting 15 minute exposure time at different $\mathrm{T}_{\text {trans }}$ temperatures: a) $80{ }^{\circ} \mathrm{C}$, b) $100{ }^{\circ} \mathrm{C}$, c) $120^{\circ} \mathrm{C}$ and d) $140{ }^{\circ} \mathrm{C}$. Trajectory color coded for time: from red (t=0 s) to dark blue.

Then, the effect of temperature was investigated (Figure 8). To that end, an exposure time of 15 minutes was set in isothermal conditions under load, and experiments were carried out at four different $\mathrm{T}_{\text {trans }}\left(80{ }^{\circ} \mathrm{C}, 100\right.$ ${ }^{\circ} \mathrm{C}, 120{ }^{\circ} \mathrm{C}$ and $140{ }^{\circ} \mathrm{C}$ ). In Figure $9 \mathrm{~b}$ the calculated $\mathrm{Rr}$ and $\mathrm{Rf}$ are provided. It was evident that as temperature was increased the stress relaxation was enhanced and samples creeped, leading to extended strains after each cycle. Higher temperatures made the differences between cycles more pronounced. $\mathrm{The} \mathrm{Rr}$ was reduced from $97 \%$ at $80{ }^{\circ} \mathrm{C}$ to $20 \%$ at $140{ }^{\circ} \mathrm{C}$. The relaxation time of E25 at $140{ }^{\circ} \mathrm{C}$ was determined to 
be $3.8 \mathrm{~min}$ according to the corresponding Arrhenious plot, which explains the poor recovery. Regarding the Rf, the calculations pointed that the fixity was improved at higher temperature, but these numbers are just the consecuence of the lower influence of the thermal shrinkage on highly strained and yielded samples.

a)

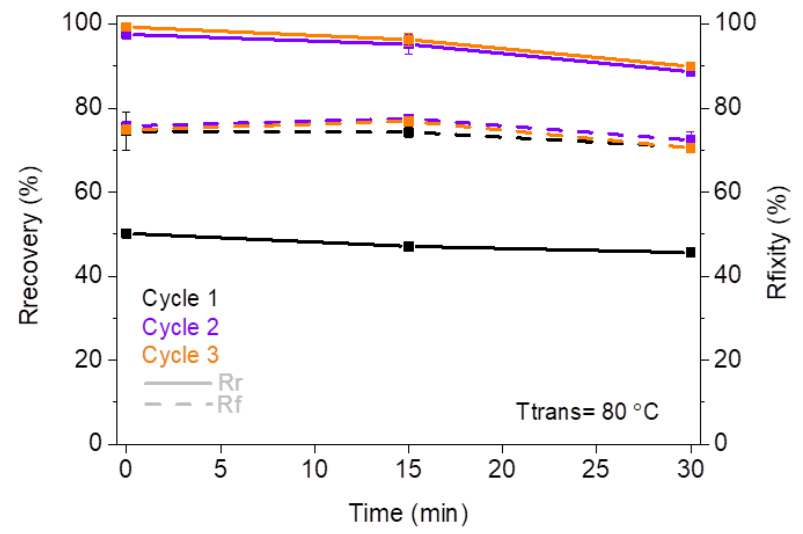

b)

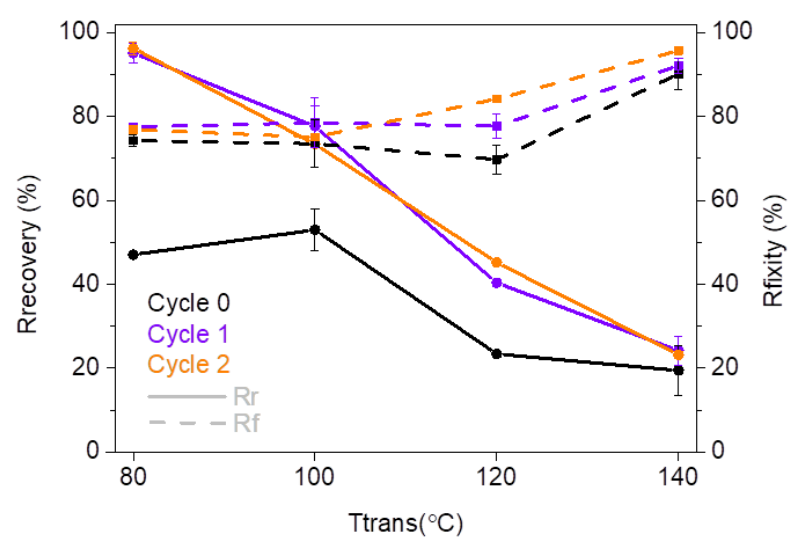

Figure 9: Calculated Rr and Rf at different testing parameters: a) Exposure time. b) $\mathrm{T}_{\text {trans. }}$.

\section{Conclusions}

Here we showed that the selection of flexible epoxy monomer combined with the widely used DGEBA allows to tune the molecular structure, crosslinking density and viscoelastic properties of aromatic disulfide based vitrimers, such as, $T_{g}$ and $T_{v}$ temperatures. $T_{v}$ temperatures of all the networks were lower than the corresponding $\mathrm{T}_{\mathrm{g}}$, indicating that aromatic disulfide exchange takes place as soon as molecular motion is gained by the network. The ease of synthesis of aromatic disulfide vitrimers (considering the wide pool of epoxy monomers available) allows designing materials with dynamic properties and shape memory programing conditions accommodated to transition temperatures of interest. More importantly, the recovery rate of the samples can be tuned by the partial stress relaxation that can be induced on them during shape programing step. Therefore, we consider that aromatic disulfide vitrimers can be regarded as versatile materials with highly tunable shape properties.

\section{Conflicts of interest}

There are no conflicts to declare. 


\section{Acknowledgements}

This work has been financially supported by the Office of Naval Research (ONR) under award number N62909-18-1-2056.

\section{Data availability statement}

The raw/processed data required to reproduce these findings cannot be shared at this time due to technical or time limitations.

\section{Electronic Supporting Information}

\section{FTIR spectra}

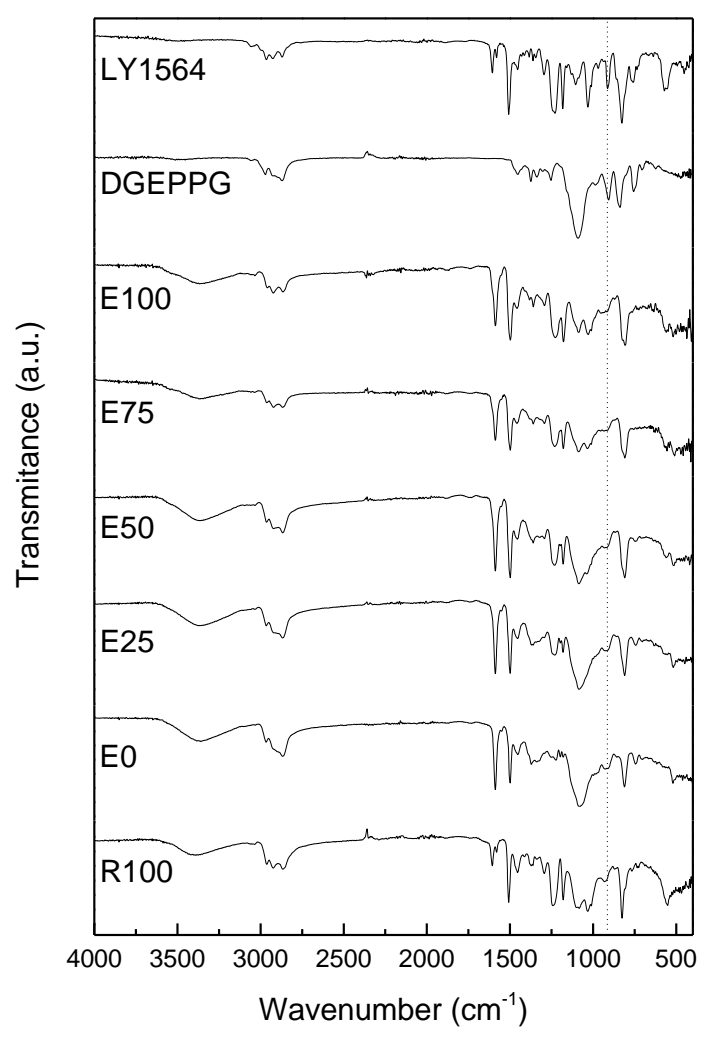

ESI Figure 1: FTIR spectra of starting epoxy monomers and cured resins. 
TGA isotherms

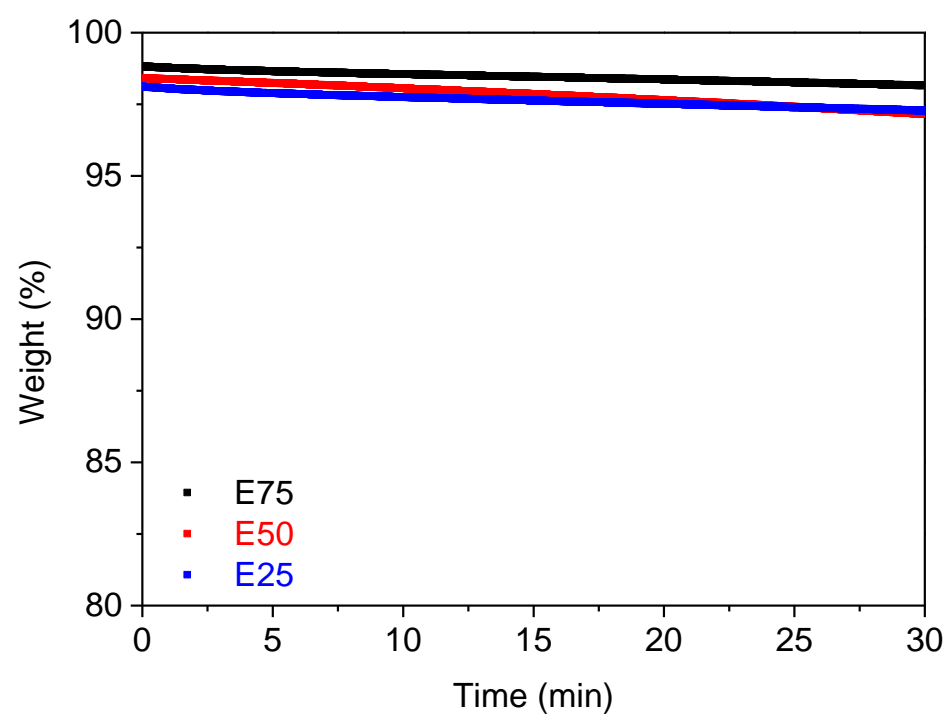

ESI Figure 2: Isotherms at $200{ }^{\circ} \mathrm{C}$ under air atmosphere of E75, E50 and E25. 


\section{Water absortion}
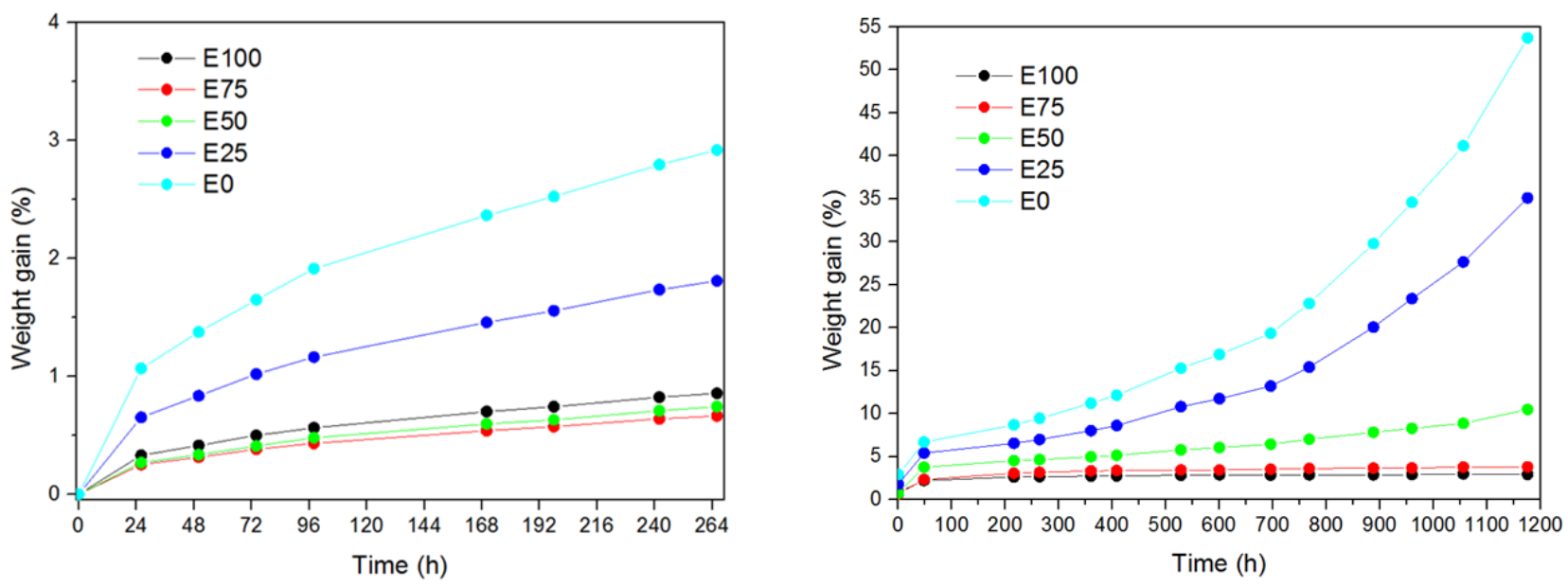

ESI Figure 3: Water uptake of E seiesepoxy networks in water: a) At ambient temperature for 11 days. b) At $80{ }^{\circ} \mathrm{C}$ for 50 days.

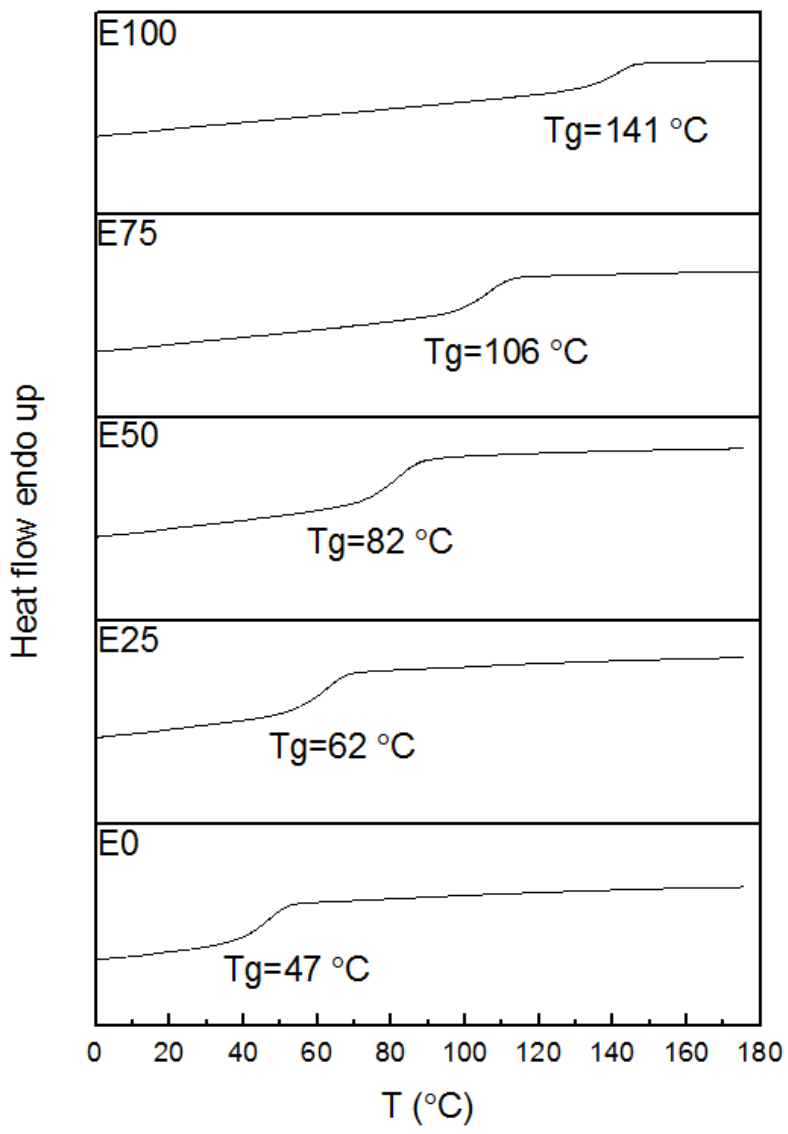

ESI Figure 4: $\mathrm{T}_{\mathrm{g}}{ }^{\mathrm{DSC}}$ measurements of dried specimens after water absorption testing.

ESI Table 1: $\mathrm{T}_{\mathrm{g}}$ DSC pristine and tested (water absorption) specimens.

\begin{tabular}{c|c|c|c|c|c}
\hline & E100 & E75 & E50 & E25 & E00 \\
\hline Reference: $\mathbf{T}_{\mathbf{g}}{ }^{\mathbf{D S C}}\left({ }^{\circ} \mathbf{C}\right)$ & 140 & 105 & 75 & 56 & 39 \\
\hline After water absoption test: $\mathbf{T}_{\mathbf{g}}{ }^{\text {DSC }}\left({ }^{\circ} \mathbf{C}\right)$ & 141 & 106 & 82 & 62 & 47 \\
\hline
\end{tabular}


Reprocessability in hot plate press

R100 $190^{\circ} \mathrm{C} / 100$ bar

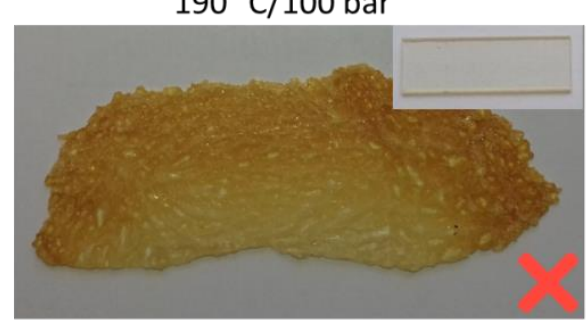

E50 $180^{\circ} \mathrm{C} / 100 \mathrm{bar}$

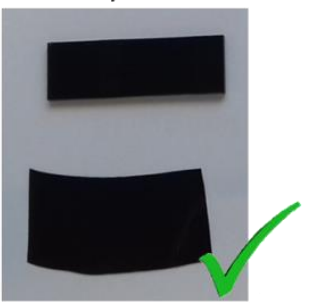

E100 $190^{\circ} \mathrm{C} / 100$ bar $\quad 190^{\circ} \mathrm{C} / 100 \mathrm{bar}$

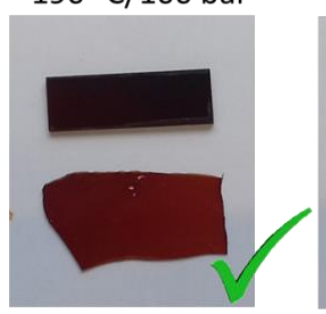

E25

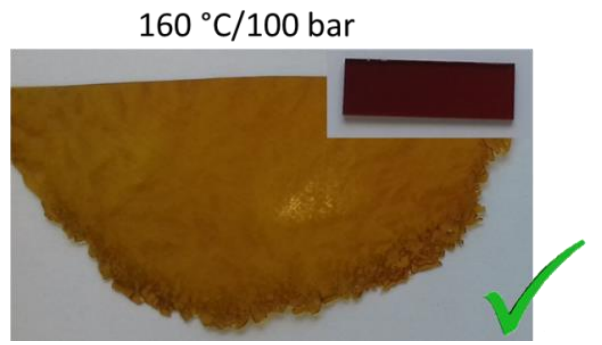

E75

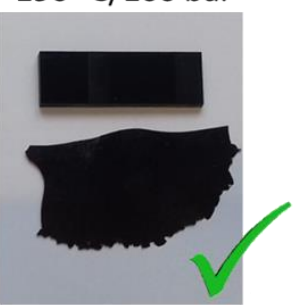

EO $140^{\circ} \mathrm{C} / 100 \mathrm{bar}$

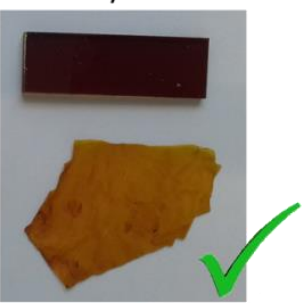

ESI Figure 5: Reprocessability tests (10 min) in a hot plate press of R100 thermoset and E series vitrimers. 
Determination of linear viscoelastic region

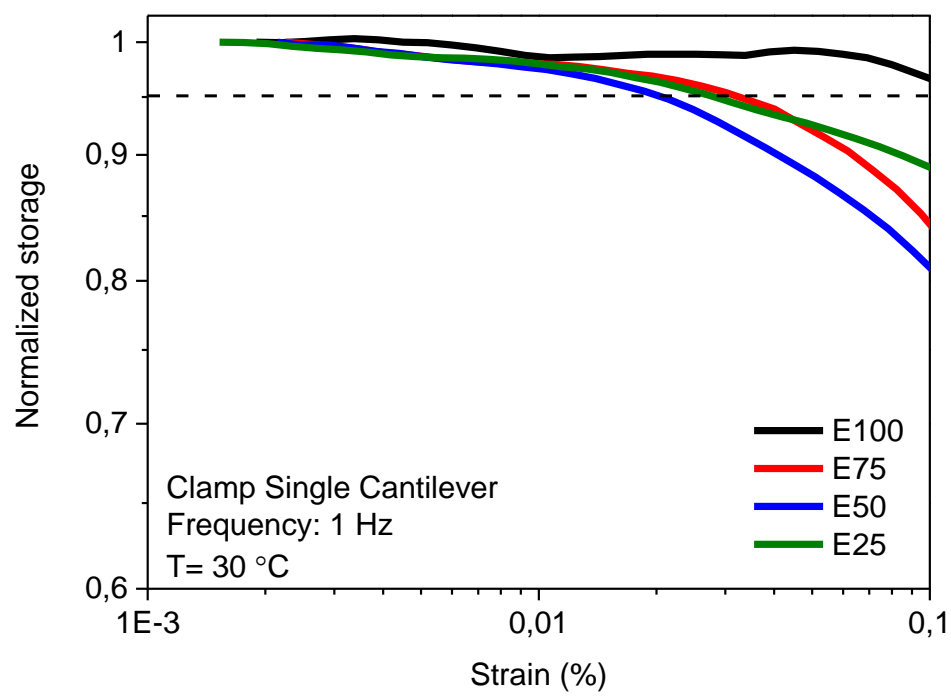

ESI Figure 6: Determination of linear viscoelastic region (LVR) of E100, E75, E50 and E25. 

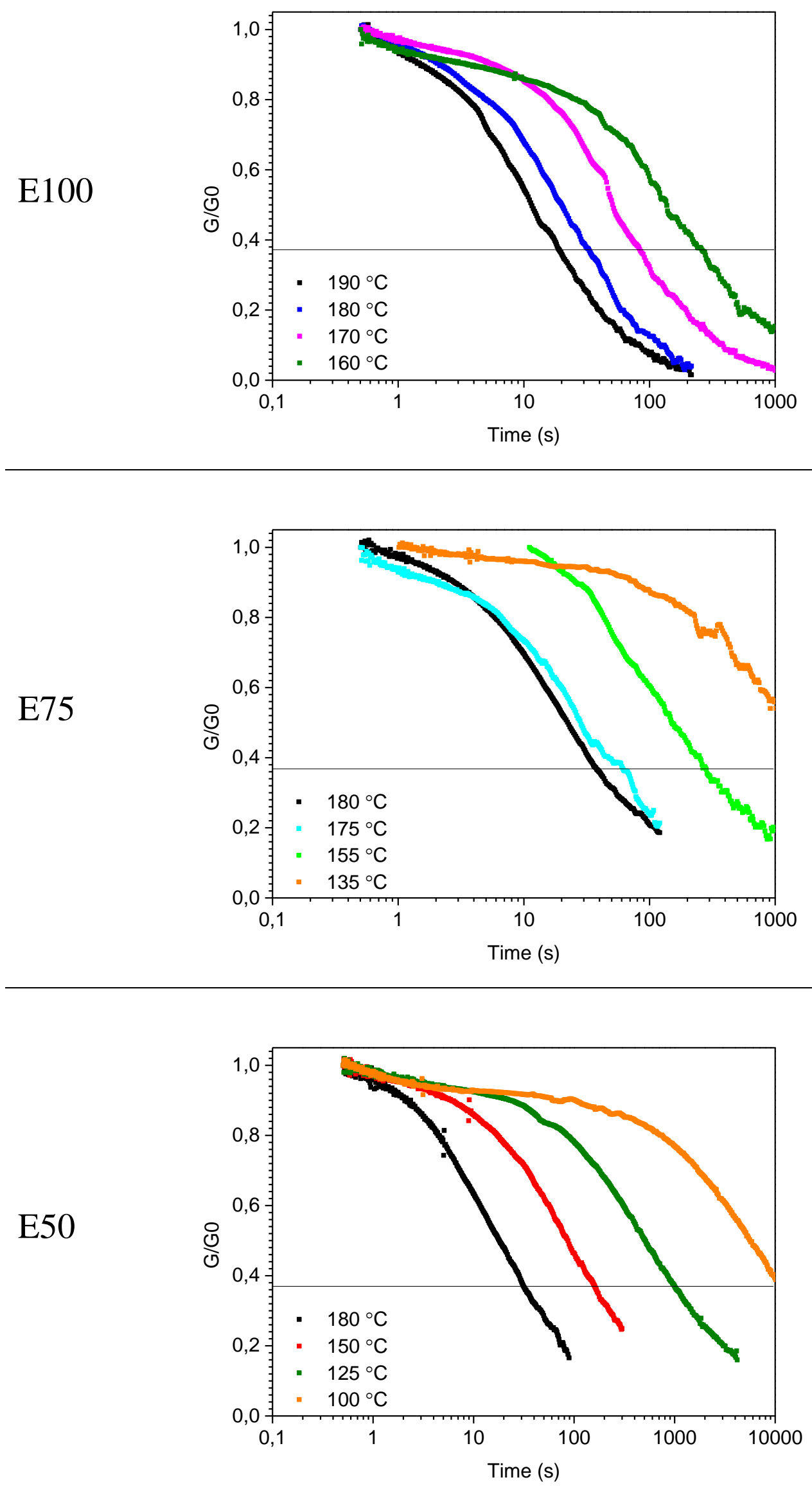

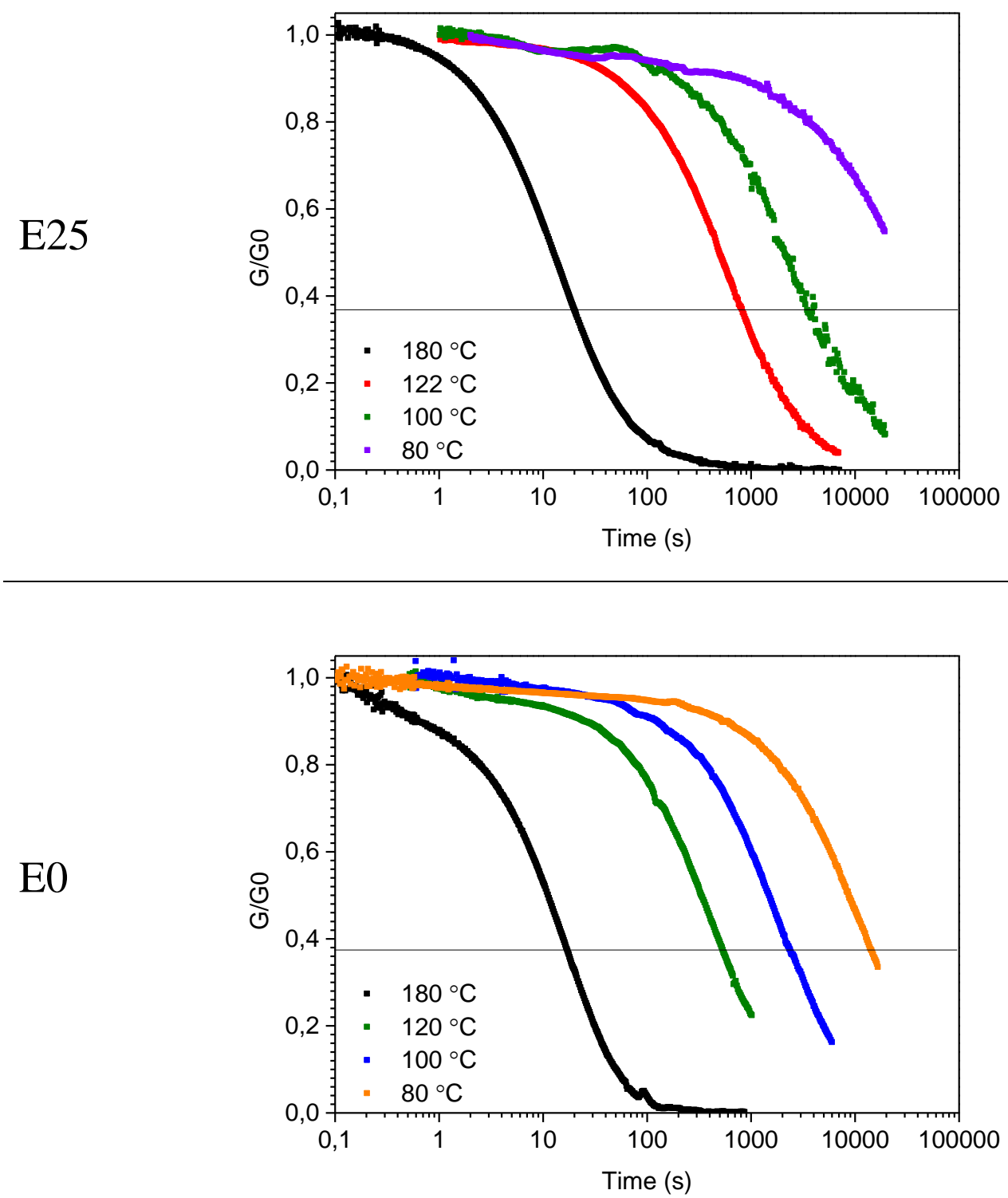

ESI Figure 7: Normalized stress relaxation curves of E100, E75, E50, E25 and E0 at different temperatures. 


\section{Determination of $\mathbf{T v}$}

$\mathrm{T}_{\mathrm{v}}$ was determined from Arrhenius' fitted line using a relaxation time calculated from the Maxwell equation. The Maxwell relation $\eta=G \tau^{*}$, correlates the viscosity $\left(\eta=10^{12} \mathrm{~Pa} s\right)$ with relaxation time, $G$ being the shear modulus. G was calculated from the tensile modulus (E') as measured by DMA from the relation $\mathrm{G}=\mathrm{E}^{\prime} / 2(1+\mathrm{v})$; with $\mathrm{v}=0.5$, the Poisson ratio usually used for rubbers.

ESI Table 2: Calculation of Tv of networks.

\begin{tabular}{llll}
\hline Ref & $\mathbf{E}^{\prime}\left(\mathbf{1 0}^{\mathbf{6}} \mathbf{P a}\right) \mathbf{a t} \mathbf{T}_{\mathbf{g}}{ }^{\text {DMA }} \mathbf{+ 3 0}^{\circ} \mathbf{C}$ & $\boldsymbol{\tau}^{*}\left(\mathbf{1 0}^{\mathbf{5}} \mathbf{s}\right) \mathbf{a t} \boldsymbol{\eta}=\mathbf{1 0}^{\mathbf{1 2}} \mathbf{P a . s}$ & $\mathbf{T}_{\mathbf{v}}\left({ }^{\circ} \mathbf{C}\right)$ \\
\hline E100 & 25 & 1.2 & 101 \\
\hline E75 & 17 & 1.7 & 95 \\
\hline E50 & 12 & 2.5 & 65 \\
\hline E25 & 6 & 2.7 & 53 \\
\hline E0 & 4 & 2.1 & 38 \\
\hline
\end{tabular}




\section{Determination of $\mathbf{R f}$ and $\mathrm{Rr}$}

ESI Table 3: Measured strain values at thermo mechanical cycles of E25 under different test conditions.

Round 1:

\begin{tabular}{|c|c|c|c|c|c|c|}
\hline Conditions: & $\begin{array}{c}80^{\circ} \mathrm{C} \\
15 \mathrm{~min}\end{array}$ & $\begin{array}{l}100^{\circ} \mathrm{C} \\
15 \mathrm{~min}\end{array}$ & $\begin{array}{l}120^{\circ} \mathrm{C} \\
15 \mathrm{~min}\end{array}$ & $\begin{array}{l}140^{\circ} \mathrm{C} \\
15 \mathrm{~min}\end{array}$ & $\begin{array}{l}80^{\circ} \mathrm{C} \\
0 \mathrm{~min}\end{array}$ & $\begin{array}{c}80^{\circ} \mathrm{C} \\
30 \mathrm{~min}\end{array}$ \\
\hline Specimen section $\left(\mathrm{mm}^{2}\right)$ : & 11.73 & 11.74 & 13.87 & 12.46 & 11.85 & 13.78 \\
\hline \multicolumn{7}{|l|}{ Cycle 1} \\
\hline$\varepsilon 0$ & 0 & 0 & 0 & 0 & 0 & 0 \\
\hline cload & 3,531 & 3,587 & 5,164 & 10,93 & 3,032 & 2,956 \\
\hline Eunload & 2,669 & 2,436 & 3,777 & 10,25 & 2,124 & 2,059 \\
\hline Erec & 1,398 & 1,263 & 2,862 & 8,861 & 1,075 & 1,106 \\
\hline \multicolumn{7}{|l|}{ Cycle 2} \\
\hline$\varepsilon 0$ & 1,398 & 1,263 & 2,862 & 8,861 & 1,075 & 1,106 \\
\hline Eload & 3,566 & 4,038 & 6,75 & 17,6 & 3,109 & 3,07 \\
\hline Eunload & 2,77 & 2,93 & 5,447 & 16,55 & 2,324 & 2,16 \\
\hline Erec & 1,434 & 1,718 & 4,409 & 14,96 & 1,114 & 1,226 \\
\hline \multicolumn{7}{|l|}{ Cycle 3} \\
\hline$\varepsilon 0$ & 1,434 & 1,718 & 4,409 & 14,96 & 1,114 & 1,226 \\
\hline Eload & 3,614 & 4,487 & 8,025 & 24,03 & 3,114 & 3,154 \\
\hline Eunload & 2,805 & 3,369 & 6,76 & 22,99 & 2,328 & 2,223 \\
\hline عrec & 1,464 & 2,157 & 5,697 & 21,13 & 1,123 & 1,327 \\
\hline
\end{tabular}

\begin{tabular}{|c|c|c|c|c|c|c|}
\hline $\mathrm{RfC} 1$ & 75,6 & 67,9 & 73,1 & 93,8 & 70,0 & 69,6 \\
\hline $\mathrm{RrC1}$ & 47,6 & 48,1 & 24,2 & 13,5 & 49,4 & 46,3 \\
\hline $\mathrm{RfC2}$ & 77,7 & 72,6 & 80,7 & 94,0 & 74,7 & 70,4 \\
\hline $\mathrm{RrC2}$ & 97,4 & 72,7 & 40,1 & 20,7 & 96,9 & 88,6 \\
\hline $\mathrm{RfC}$ C3 & 77,6 & 75,1 & 84,2 & 95,7 & 74,8 & 70,5 \\
\hline $\mathrm{RrC3}$ & 97,8 & 73,4 & 45,2 & 23,2 & 99,3 & 89,9 \\
\hline
\end{tabular}

Round 2:

\begin{tabular}{|c|c|c|c|c|c|c|}
\hline Conditions: & $\begin{array}{c}80^{\circ} \mathrm{C} \\
15 \mathrm{~min}\end{array}$ & $\begin{array}{l}100^{\circ} \mathrm{C} \\
15 \mathrm{~min}\end{array}$ & $\begin{array}{l}120^{\circ} \mathrm{C} \\
15 \mathrm{~min}\end{array}$ & $\begin{array}{l}140^{\circ} \mathrm{C} \\
15 \mathrm{~min}\end{array}$ & $\begin{array}{l}80^{\circ} \mathrm{C} \\
0 \mathrm{~min}\end{array}$ & $\begin{array}{c}80^{\circ} \mathrm{C} \\
30 \mathrm{~min}\end{array}$ \\
\hline Specimen section $\left(\mathrm{mm}^{2}\right)$ : & 10.81 & 10.43 & 11.39 & 13.48 & 11.65 & 13.78 \\
\hline \multicolumn{7}{|l|}{ Cycle 1} \\
\hline$\varepsilon 0$ & 0 & 0 & 0 & 0 & 0 & 0 \\
\hline cload & 5,89 & 3,918 & 5,279 & 7,706 & 2,997 & 3,765 \\
\hline eunload & 4,29 & 3,1 & 3,505 & 6,667 & 2,368 & 2,701 \\
\hline erec & 2,29 & 1,307 & 2,715 & 4,972 & 1,162 & 1,486 \\
\hline \multicolumn{7}{|l|}{ Cycle 2} \\
\hline$\varepsilon 0$ & 2,29 & 1,307 & 2,715 & 4,972 & 1,162 & 1,486 \\
\hline cload & 6,04 & 4,315 & 6,637 & 11,64 & 3,192 & 3,96 \\
\hline Eunload & 4,67 & 3,645 & 4,958 & 10,51 & 2,447 & 2,943 \\
\hline grec & 2,46 & 1,713 & 4,047 & 8,978 & 1,186 & 1,651 \\
\hline
\end{tabular}




\begin{tabular}{|c|c|c|c|c|c|c|}
\hline $\mathrm{RfC1}$ & 72,9 & 79,1 & 66,4 & 86,5 & 79,0 & 71,74 \\
\hline $\mathrm{RrC1}$ & 46,6 & 57,8 & 22,5 & 25,4 & 50,9 & 44,98 \\
\hline $\mathrm{Rf} C 2$ & 77,3 & 84,5 & 74,7 & 90,3 & 76,7 & 74,32 \\
\hline $\mathrm{RrC2}$ & 92,9 & 82,6 & 40,6 & 27,7 & 98,1 & 88,68 \\
\hline
\end{tabular}

\section{References}

[1] Q. Zhao, W. Zou, Y. Luo, T. Xie, Shape memory polymer network with thermally distinct elasticity and plasticity, Sci Adv 2 (2016) 1 e1501297

[2] P. T. Mather, X. Luo, I. A. Rousseau, Shape memory polymer research, Annu Rev Mater Res 39 (2009) 445-471.

[3] F. Pilate, A. Toncheva, P. Dubois, J. M. Raquez, Shape-memory polymers for multiple applications in the materials world, Eur Polym J 80 (2016) 268-294.

[4] S.J. Rowan, S. J. Cantrill, G. R. L. Cousins, J. K. M. Sanders, J. Fraser Stoddart, Dynamic Covalent Chemistry, Angew Chem Int Ed 41 (2002) 898-952.

[5] J.M. Lehn, Dynamers: dynamic molecular and supramolecular polymers, Prog Polym Sci 30 (2005) 814831.

[6] T. Maeda, H. Otsuka, A. Takahara, Dynamic covalent polymers: Reorganizable polymers with dynamic covalent bonds, Prog Polym Sci 34 (2009) 581-604.

[7] C. J. Kloxin, T. F. Scott, B. J. Adzima, C. N. Bowman, Covalent Adaptable Networks (CANs): A Unique Paradigm in Cross-Linked Polymers, Macromolecules 43 (2010) 2643-2653.

[8] D. Montarnal, M. Capelot, F. Tournilhac, L. Leibler, Silica-like malleable materials from permanent organic networks, Science 334 (2011) 965-968.

[4-9] W. Denissen, J. M. Winne, F. E. Du Prez, Vitrimers: Permanent organic networks with glass-like fluidity, Chem Sci 7 (2015) 30-38.

[510] W. Zou, J. Dong, Y. Luo, Q. Zhao, T. Xie, Dynamic covalent polymer networks: from old chemistry to modern day innovations, Adv Mater 29 (2017) 1606100.

[611] J. C. Dyre, The glass transition and elastic models of glass forming liquids, Rev Mod Phys 78 (2006) 953.

[712] C. A. Angell, Formation of glasses from liquids and biopolymers, Science 267 (1995) 1924-1935.

[813] M. D. Ediger, C. A. Angell, S. R. Nagel, Supercooled liquids and glasses, J Phys Chem 100 (1996) 13200-13212.

[914] M. Guerre, C. Taplan,J. M. Winne, F. E. DuPrez, Vitrimers: directing chemical reactivity to control material properties, Chem Sci 11 (2020) 4855-4870. 
[1015] F. I. Altuna, C. E. Hoppe, R. J. J. Williams, Shape memory epoxy vitrimers based on DGEBA crosslinked with dicarboxylic acids and their blends with citric acid, RSC Adv 6 (2016) 88647-88655.

[1116] T. Liu, C. Hao, L. Wang, Y. Li, W. Liu, J. Xin, J. Zhang, Eugenol-derived biobased epoxy: Shape memory, repairing and recyclability, Macromolecules 50 (2017) 8588-8597.

[1217] S. Zhang, T. Liu, C. Hao, L. Wang, J. Han, H. Liu, J. Zhang, Preparation of a lignin-based vitrimer material and its potential use for recoverable adhesives, Green Chem 20 (2018) 2995-3000.

[1318] Z. Yang, Q. Wang, T. Wang, Dual-triggered and thermally reconfigurable shape memory graphenevitrimer composites, ACS Appl Mater Interfaces 8 (2016) 21691-21699.

[1419] A. Li, J. Fan, G. Li, Recyclable thermoset shape memory polymers with high stress and energy output: Via facile UV-curing, J Mater Chem A 6 (2018) 11479-11487.

[1520] T. F. Scott, A. D. Schneider, W. D. Cook, C. N. Bowman, Photoinduced plasticity in cross-linked polyners, Science 308 (2005) 1615-1617.

[1621] A. Rekondo, R. Martin, A. Ruiz de Luzuriaga, Germán Cabañero, Hans J. Grande, I. Odriozola, Catalyst-free room temperatura self-healing elastomers base on aromatic disulfide metathesis, Materials Horizons 1 (2014) 237-240.

[1722] A. Ruiz de Luzuriaga, R. Martin, N. Markaide, A. Rekondo, G. Cabañero, J. Rodríguez, I. Odriozola, Materials Horizons 3 (2016) 241-247. b) A. Ruiz de Luzuriaga, R. Martin, N. Markaide, A. Rekondo, G. Cabañero, J. Rodríguez, I. Odriozola, Materials Horizons. DOI: 10.1039/D0MH90047H.

[1823] Z. Ma, Y. Wang, J. Zhu, J. Yu, Z. Hu, Bio-based epoxy vitrimers: Reprocessibility, controllable shape memory, and degradability, J Polym Sci Part A Polym Chem 55 (2017) 1790-1799.

[1924] F. Ji, X. Liu, D. Sheng, Y. Yang, Epoxy-vitrimer composites based on exchangeable aromatic disulfide bonds: Reprocessibility, adhesive, multi-shape memory effect, Polymer 197 (2020) 122514.

[25] H. Memon, Y. Wei, Welding and reprocessing of disulfide-containing thermoset epoxy resin exhibiting behavior reminiscent of a thermoplastic, J Appl Polym Sci (2020) e49541.

[26] A. Genua, S. Montes, I. Azcune, A. Rekondo, S. Malburet, B. Daydé-Cazals, A. Graillot, Build-tospecification vanillin and phloroglucinol derived biobased epoxy-amine vitrimers, Polymers 12 (2020) 2645.

[27] C. Di Mauro, S. Malburet, A. Graillot, A. Mija, Recyclable, repairable, and reshapable (3R) thermoset materials with shape memory properties from bio-based epoxidized vegetable oils, ACS Appl Bio Mater 3 (2020) 8094-8104.

[28] H. Si, L. Zhou, Y. Wu, L. Song, M. Kang, X. Zhao, M. Chen, Rapidly reprocessable, degradable epoxy vitrimer and recyclable carbon fiber reinforced thermoset composites relied on high contents of exchangeable aromatic disulfide crosslinks, Composite Part B: Engineering 199 (2020) 108278.

[29] Y. Spiesschaert, C. Taplan, L. Stricker, M. Guerre, J. M. Winne, F. E. Du Prez, Influence of the vitrimer matrix on the viscoelastic behavior of vitrimers, Polym Chem 11 (2020) 5377-5385.

[2030] T. Xie, I. A. Rousseau, Facile tailoring of thermal transition temperatures of epoxy shape memory polymers, Polymer 50 (2009) 1852-1856.

[2131] F.W.A. Su, K.C. Chen, S.Y. Tseng, Effects of chemical structure changes on thermal, mechanical, and crystalline properties of rigid rod epoxy resins. J Appl Polym Sci 78 (2000) 446-451. 
[2232] J. M. Matxain, J. M. Asua, F. Ruiperez, Design of new disulfide-based organic compounds for the improvement of self-healing materials, Phys Chem Chem Phys 18 (2016), 1758-1770.

[2333] S. Nevejans, N. Ballard, J. I. Miranda, B. Reck, J. M. Asua, The underlying mechanism for self healing of poly(disulfide)s, Phys Chem Chem Phys 18 (2016), 27577-27583. 